\title{
Alguns Modelos Determinísticos \\ de Transmissão de \\ Doenças Infecciosas
}

\section{Ariovaldo José de Almeida}

\author{
DISSERTAÇÃO APRESENTADA \\ $\mathrm{AO}$ \\ INSTITUTO DE MATEMÁTICA E ESTATÍSTICA \\ DA \\ UNIVERSIDADE DE SÃO PAULO \\ PARA OBTENCSO DO GRAU \\ DE \\ MESTRE EM MATEMÁTICA APLICADA
}

Área de Concentração: Sistemas Dinâmicos Orientador: Prof. Dr. Antônio Luiz Pereira

Durante a elaboraçào deste trabalho.

o autor recebeu apoio financeiro da C.APES e do C.VPQ

- São Paulo, agosto de 1997 - 


\section{Alguns Modelos Determinísticos \\ de Transmissão de \\ Doenças Infecciosas}

Este exemplar corresponde à redação final

da dissertaçào devidamente corrigicla e

defendida por Ariovaldo José de Almeida.

e aprovada pela comissão julgadora.

Sào Paulo, 29 de agosto de 1997.

Banca examinadora:

- Prof a . Dro . Antônio Luiz Pereira (Orientador) - IME - USP

- Profa. Dr a Élvia Mureb Sallum - IME - USP

- Profạ Dra a. Maria Aparecida Bená - FFCLRP - USP 
Aos meus pais Ariovaldo e Iracema 


\section{Agradecimentos}

Minha iniciação no estudo sobre propagaçào de doenças infecciosas começou quando participei como aluno de iniciação científica de um projeto denominado NUPTEM - Núcleo de Pesquisa Taxonômica e Sistemática em Entomologia Médica -. sob orientação da Prof. Élvia Mureb Sallum e cujo Coordenador Prof. Osvaldo Paulo Forattini sugeriu o estudo de alguns temas. À eles, minha gratidão e consideração.

Ao Prof. Antônio Luiz Pereira pela orientaçào e paciência sem as quais este trabalho nào teria sido possível.

Ao Prof. Cláudio Santos Ferreira e Maria Esther de Carvalho pela amizade e companheirismo.

Aos amigos Carlos Juiti Watanabe e Gaspar A. S. Pacho pela imprescindível ajuda na parte computacional.

Aos amigos, professores e funcionários que colaboraram com a realização dessa obra. obrigado. 


\section{Resumo}

Neste trabalho consideramos alguns modelos determinísticos de propagação de moléstias infecciosas do tipo SIR ou correlatos.

Estudamos, em particular, alguns aspectos do comportamento assintótico, entre os cuais existência e estabilidade de pontos críticos e órbitas periódicas.

\section{Abstract}

In this work we consider some deterministic models of propagation of infectious disease of the SIR type or correlates.

We study, in particular. some aspects of the asymptotic behavior. such as existence and stability of critical points and periodic orbits. 


\section{Sumário}

Introdução

1 Um Modelo Determinístico para Gonorréia em uma População Não Homogênea $\quad 1$

1.1 Preliminares . . . . . . . . . . . . . . . . . . 1

1.2 Fatores Epidemiológicos Relevantes . . . . . . . . . . 2

1.3 Conclusões sobre Gonorréia . . . . . . . . . . . . . . 3

1.4 Propriedades Epidemiológicas Básicas da Gonorréia . . . . . . 3

1.5 O Modelo n-Dimensional . . . . . . . . . . . . . . 4

1.6 Comportamento Assintótico . . . . . . . . . . . . . . 8

2 Um Modelo de Transmissão de Doença em Uma População $\begin{array}{ll}\text { Não Constante } & 18\end{array}$

2.1 Preliminares . . . . . . . . . . . . . . . . . 18

2.2 Um Modelo Geral SIRS . . . . . . . . . . . . . . . . . . 19

2.3 Não Existência de Soluções Periódicas . . . . . . . . . . . . 21

2.4 Um Modelo SIRI . . . . . . . . . . . . . . . . . . 26

2.5 Soluções Periódicas . . . . . . . . . . . . . . . 30

3 Um Modelo de Transmissão de HIV e AIDS 41

3.1 Preliminares . . . . . . . . . . . . . . . . . . 41

3.2 Informações Gerais sobre o HIV e AIDS . . . . . . . . . . . . 42

3.3 Modelando a Progressão de Pessoas com HIV à AIDS . . . . . 43

3.4 Formulação do Modelo . . . . . . . . . . . . . . . . . . 46

3.5 Análise Matemática do Modelo . . . . . . . . . . . . . . 47

3.5.1 Estabilidade do Equilíbrio Livre de Doença DFE . . . . 50

3.5.2 Estabilidade do Equilíbrio Endêmico EE . . . . . . . . 55 
A Resultados Técnicos. $\quad 60$

A.1 O Teorema de Perron-Frobenius . . . . . . . . . . . . 60

A.2 Princípio da Invariância de La Salle . . . . . . . . . . . . 61

A.3 Estabilidade de Pontos Críticos. . . . . . . . . . . . 63

A.4 O Teorema de Bifurcação de Hopf. . . . . . . . . . . . . . . 64

$\begin{array}{ll}\text { Referências Bibliográficas } & 66\end{array}$ 


\section{Introdução}

O objetivo deste trabalho é descrever alguns modelos de propagação de uma infecção em uma população.

Dentro desse contexto, trabalharemos essencialmente com modelos determinísticos e compartimentais, isto é, modelos que utilizam equações diferenciais para descrever as mudanças na população e dividem a população hospedeira em compartimentos, como por exemplo, suscetíveis, infectivos e imunes.

Um importante conceito nesse estudo é o número reprodutivo básico $R_{0}$, que fornece o número de infecções secundárias produzidas por um único indivíduo infectado em uma população inteiramente suscetível ao agente infeccioso.

A importância desse conceito e análogos reside no fato de servirem como um parâmetro de limiar para a ocorrência ou não de uma epidemia, determinando a transição para uma situação na qual uma infecção possui potencial para se tornar epidêmica e assim tornando difícil o controle ou erradicação do agente infeccioso.

Para ilustrar os comentários acima faremos uma breve análise do modelo elaborado por W. O. Kermack e A. G. McKendrick (1927) que foram pioneiros no estudo de epidemias.

Esse modelo lida com uma doença como o sarampo que é transmitida através do contato com indivíduos infectados.

A população é dividida em três compartimentos ou classes: suscetíveis $(S)$ que podem contrair a doença, infectivos $(I)$ que podem transmitir a doença para outros e os removidos $(R)$ que tiveram a doença e estão isolados ou adquiriram imunidade ou morreram.

Esse esquema é comumente chamado de modelo SIR, seqüência de letras que descrevem o movimento de indivíduos entre as classes: suscetíveis tornam-se infectados e então tornam-se removidos. 
A população tem tamanho fixo $N$. onde

$$
N=S+I+R
$$

para qualquer tempo $t$, tomado como contínuo, ou seja, $t \in \mathbb{R}$.

A propagação da infecção é determinada pelas seguintes hipóteses:

i) Suscetiveis tornam-se infectivos a uma taxa que é proporcional ao produto do número de suscetíveis e infectivos. ou seja, $\beta S I$, onde $\beta$ é referido como taxa de infecção.

ii) Infectivos são removidos a uma taxa proporcional ao seu número, ou seja, $\gamma I$, onde $\gamma$ é a taxa de remoção.

Essas hipóteses conduzem ao seguinte sistema de equações diferenciais:

Modelo Determinístico SIR

$$
\left\{\begin{array}{l}
S^{\prime \prime}=-\beta S I, \\
I^{\prime}=\beta S I-\gamma I, \\
R^{\prime}=\gamma I,
\end{array}\right.
$$

onde $S, I, R$ são o número de suscetíveis, infectivos e removidos, respectivamente, $\beta$ é a taxa de infecção e $\gamma$ é a taxa de remoção.

Da Equação 0.2 temos que:

$$
I^{\prime}=I(\beta S-\gamma)
$$

portanto se $S^{\prime}>\gamma / \beta$ então $I^{\prime}>0$ e assim podemos afirmar que ocorrerá epidemia quando o número reprodutivo básico exceder a unidade, ou seja,

$$
R_{0}=\frac{\beta S_{0}}{\gamma}>1
$$

onde $S_{0}$ é o número inicial de suscetiveis.

Maiores detalhes sobre esse modelo podem ser encontrados em [28] ou no artigo original de Kermack e McKendric [17].

Seguindo essa mesma linha de estudo, no Capítulo 1 fazemos uma análise de um modelo de transmissão de gonorréia. A população é dividida em grupos e aos contatos entre esses grupos está associada uma matriz de tal forma que quando o módulo de estabilidade dessa matriz. ou seja, o máximo do conjunto formado pela parte real dos autovalores da matriz. é estritamente positivo 
então a doença permanece endêmica, caso contrário. quaisquer que sejam as condiçòes iniciais a doença extingue-se. Portanto o módulo de estabilidade serve como uma quantidade limiar.

No Capítulo 2, um modelo de transmissào SIRS é analisado para uma população variável. A taxa de incidência é nào-linear e a classe dos removidos pode ser reinfectada diretamente. Assim, para uma classe de funções incidência mostramos que o modelo não possui órbitas periódicas. Por outro lado, para uma particular função incidência, uma combinação de técnicas analíticas revelam que, para alguns parâmetros, podemos ter soluções periódicas, sendo que a estabilidade dessas soluções são estudadas via bifurcação de Hopf sub ou super-crítica.

O Capítulo 3 trata de um modelo de transmissão de HIV/AIDS na qual a população progride através de uma seqüência de fases. Definimos o número de contato, número médio de contatos adequados de um infectivo durante todo seu período infeccioso, e mostramos que ele faz o papel de uma quantidade limiar, ou seja, demonstramos que para valores menores ou iguais a 1 a doença extingue-se e para valores maiores do que 1 demonstramos que, sob algumas hipóteses, a doença torna-se endêmica.

Finalmente, reunimos no Apêndice alguns resultados técnicos necessários em várias partes do texto. 


\section{Capítulo 1}

\section{Um Modelo Determinístico para Gonorréia em uma População Não Homogênea}

\subsection{Preliminares}

As doenças variam bastante em relação à facilidade de modelagem matemática.

Sarampo, caxumba e catapora são relativamente simples porque um indivíduo recuperado é imune a uma reinfecção e, assim, pode ser ignorado no modelo.

A gonorréia é relativamente simples por uma razão diferente. Pessoas recuperam-se desta doença somente após tratamento terapêutico e não desenvolvem nenhuma resistência observável à doença. Após recuperação, elas imediatamente tornam-se suscetíveis.

O período de incubação é curto, comparado com o freqüente longo período de infecciosidade ativa, podendo assim ser ignorado.

Neste capítulo trataremos de um modelo para gonorréia que foi formulado e analisado por Lajmanovich e Yorke (1976) [15]. 


\subsection{Fatores Epidemiológicos Relevantes}

A gonorréia tem três características epidemiológicas notáveis que devem ser incorporadas ao modelo.

Primeiro: trata-se de uma infecção na qual não é conferida nenhuma imunidade significativa. Desse modo, indivíduos tornam-se novamente suscetíveis tão logo eles se recuperem da infecção e os antibióticos deixem o corpo.

Há indivíduos que foram infectados e curados dez ou mais vezes em um ano. Esta falta de imunidade faz da gonorréia uma doença muito diferente de outras como sarampo, caxumba, rubéola, catapora, poliomielite, difteria, coqueluche e tétano. Como resultado dessa primeira observação não é preciso considerar a classe dos removidos, isto é. os indivíduos que foram removidos da interação suscetível-infectivo devido à aquisiçào de imunidade após cura.

Segundo: um indivíduo que adquire gonorréia torna-se infeccioso em um ou dois dias. Assim, o período latente é muito curto comparado com o período latente de aproximadamente 12 dias para sarampo, 15 dias para catapora e 18 dias para caxumba. De fato, o período latente para gonorréia é suficientemente curto para que não seja necessário incluir uma nova classe de indivíduos em um modelo para gonorréia.

Terceiro: a oscilação sazonal na incidência de gonorréia é muito pequena sendo menor que $10 \%$ (incidência é o número de novos casos em um intervalo de tempo, tais como um ano, um mês, uma semana). Em contraste, a incidência de doenças como influenza, sarampo. caxumba e catapora freqüentemente variam sazonalmente por fatores de 5 a 50 ou mais. Assim, modelos que usam valores constantes como parâmetros, tais como a taxa cle contato, fornecem boas aproximações para gonorréia.

Essas três características acima indicam que o modelo SIS com valores dos parâmetros constantes é adequado para a descrição da dinâmica de propagação da gonorréia.

Além disso, assumiremos que a população sexualmente ativa é constante em tamanho e igual ao número de infectivos mais o número de suscetíveis, onde população sexualmente ativa é formada pelos indivíduos que potencialmente podem contrair ou transmitir a doença em seus contatos. 


\subsection{Conclusões sobre Gonorréia}

Mostraremos que ou a doença extingue-se naturalmente para todos os níveis iniciais positivos da doença ou a doença permanece endêmica, para todo tempo futuro, dependendo das taxas de contato e das duraçòes dos períodos infecciosos. Neste último caso, mostraremos que se o número inicial de infectivos em pelo menos um grupo não é zero, então a doença permanecerá endêmica e o número de infectivos em cada grupo se aproximará de um nível positivo constante.

Esse comportamento epidêmico da gonorréia é diferente da maioria de outras doenças infecciosas, que normalmente ocasionam maiores surtos seguidos por baixos níveis da doença. Esse comportamento diferente é atribuído à falta de imunidade e à nào sazonalidade básica da doença .

\subsection{Propriedades Epidemiológicas Básicas da Gonorréia}

Assumiremos que são válidas as seguintes hipóteses sobre o modelo:

(i.) A doença é propagada de pessoa para "pessoa" (com a necessária interação para passar a doença de um infectivo para um suscetível).

(ii.) A probabilidade de um suscetível contactar um infectivo não varia significativamente com a época do ano.

(iii.) A probabilidade de recuperação de um indivíduo infectado em um período de tempo específico é independente do tempo desde a infecção inicial e é estritamente positiva.

Seja $P(\tau)$ a probabilidade de um indivíduo ainda estar infectado um tempo $\tau$ após a infecção inicial.

Segue da independência que:

$$
P(\tau+\eta)=P(\tau) P(\eta)
$$

Portanto

$$
P(\tau)=k e^{\beta \tau}
$$

(veja, por exemplo, [4], p. 140). Usando que $P(0)=1$ e supondo que $P$ é estritamente decrescente, temos que:

$$
P(\tau)=e^{-\tau \alpha},
$$


para alguma constante $\alpha>0$. Essa constante $\alpha$ é chamada taxa de recuperação e $\frac{1}{a}$ é chamado de período médio de infecciosidade. Como a probabilidade de recuperação durante o tempo $[\tau, \tau+d \tau]$ é $\alpha \epsilon^{-\tau \alpha} d \tau$, o tempo esperado de recuperação é então

$$
\int_{0}^{\infty} \tau e^{-\tau \alpha} \alpha d \tau=\frac{1}{\alpha}
$$

(iv.) O tamanho total da população "ativa" é constante.

(v.) O período de incubação é desprezível. Qualquer indivíduo suscetível contaminado por um infectivo imediatamente torna-se infeccioso e após recuperação imediatamente torna-se suscetível novamente sem qualquer imunidade parcial (suscetível $\rightleftharpoons$ infectivo).

Desse modo, serão considerados no modelo apenas indivíduos infectados e suscetiveis.

\subsection{O Modelo n-Dimensional}

Assumiremos que estamos lidando com uma população não-homogênea que pode ser dividida em $n$ grupos homogêneos. Cada grupo é homogêneo no sentido de que todos os indivíduos do mesmo grupo têm as mesmas taxas de contato com novos parceiros sexuais, a mesma duração média de infecção e a mesma probabilidade de adquirir a infecção durante um encontro sexual com um parceiro infectivo.

Assumiremos também que indivíduos infectivos em um grupo tem os mesmos comportamentos sexuais e níveis de atividades dos suscetíveis.

Sejam $x_{i}(t)$ o número de suscetíveis, $y_{i}(t)$ o número de infectivos, $\alpha_{i}$ a taxa de recuperação e $c_{i}$ o tamanho total da população do i-ésimo grupo.

Seja $\beta_{j i}$ a taxa de contato dos suscetiveis do i-ésimo grupo com os infectivos do j-ésimo grupo, isto é, $\beta_{j i}$ é a proporção da população suscetível do $i$-ésimo grupo que um infectivo do $j$-ésimo grupo contacta (infecta) por unidade de tempo.

Embora $\beta_{i j}$ não seja necessariamente igual a $\beta_{j i}$, assumiremos que se $\beta_{i j} \neq 0$ então $\beta_{j i} \neq 0, \forall i, j$. (Seria não realístico assumir que suscetíveis do $i$-ésimo grupo possam ser infectados por membros infecciosos do $j$-ésimo mas não vice-versa. Por outro lado, se o $i$-ésimo grupo contém somente mulheres e o $j$-ésimo grupo somente homens, então nào se pode esperar que $\beta_{j i}$ e $\beta_{i j}$ sejam iguais.) 
Definição 1 Seja $G_{i}$, onde $i=1, \ldots, n$ o conjunto de indivíduos do i-ésimo grupo. Dizemos que $G_{i}$ infecta $G_{j}$ se e somente se $3_{i j}>0$. Caso contrário, $G_{i}$ não infecta $G_{j}$.

Definição 2 Seja $G$ o conjunto de todos os individuos, isto é, $G=\bigcup_{i=1}^{n} G_{i}$. Dizemos que $G$ é ligado se, para qualquer subconjunto próprio $S$ do conjunto $\{1, \ldots, n\}$ (isto é. $S$ é nào vazio e seu complemento $S^{\prime}$ também é não vazio), existem $i$, $j$ tais que $i \in S, j \in S^{\prime \prime}$ e $\beta_{i j} \neq 0$.

Assumiremos agora sem perda de generalidade que $G$ é ligado (caso contrário estudamos cada componente ligada separadamente).

Seja $E_{j i}(t)$ a taxa de exposição para o $i$-ésimo grupo devido aos infectivos do $j$-ésimo grupo. isto é, a taxa aos quais os suscetíveis em $G_{i}$ estão sendo infectados por infectivos em $G_{j}$.

Para encontrar a equação para $y_{i}(t)$, para $i=1, \ldots, n$, notemos que em vista da observação 1.4 (iii)

$$
y_{i}(t)=\int_{0}^{t} \sum_{j=1}^{n} E_{j i}(\tau) e^{-\alpha_{i}(t-\tau)} d \tau
$$

e diferenciando (1.2),

$$
\begin{aligned}
\frac{d y_{i}(t)}{d t} & =\sum_{j=1}^{n} E_{j i}(t)+\int_{0}^{t} \sum_{j=1}^{n} E_{j i}(\tau)\left(-\alpha_{i}\right) e^{-\alpha_{i}(t-\tau)} d \tau \\
& =\sum_{j=1}^{n} E_{j i}(t)-\alpha_{i} \int_{0}^{t} \sum_{j=1}^{n} E_{j i}(\tau) e^{-\alpha_{i}(t-\tau)} d \tau .
\end{aligned}
$$

Portanto

$$
\frac{d y_{i}(t)}{d t}=\sum_{j=1}^{n} E_{j i}(t)-\alpha_{i} y_{i}(t) .
$$

Da definição de taxa de contato $E_{j i}(t)=\beta_{j i} x_{i}(t) y_{j}(t)$ e como $x_{i}(t)+y_{i}(t)=$ $c_{i}$, podemos reescrever (1.3) como

$$
\frac{d y_{i}(t)}{d t}=-\alpha_{i} y_{i}(t)+\sum_{j=1}^{n} \beta_{j i}\left(c_{i}-y_{i}(t)\right) y_{j}(t) .
$$

Portanto

$$
\frac{d y_{i}(t)}{d t}=-\alpha_{i} y_{i}(t)+\sum_{j=1}^{n} \beta_{j i} c_{i} y_{j}(t)-\sum_{j=1}^{n} \beta_{j i} y_{i}(t) y_{j}(t) .
$$


Estudaremos este sistema para $\left(y_{1}, \ldots, y_{n}\right) \in \Delta_{n}=\prod_{i=1}^{n}\left[0, c_{i}\right]$, isto é,

$$
\Delta_{n}=\left\{y \in \mathbb{R}^{n}: 0 \leq y_{i} \leq c_{i}, i=1 \ldots, n\right\} .
$$

O seguinte lema garante que o número de infectivos de cada grupo não pode tornar-se negativo, nem maior do que o tamanho total da população, ou seja, o problema (1.4) é bem posto.

Lema $1 \Delta_{n}$ é positivamente invariante para o sistema (1.4).

\section{Prova:}

Queremos mostrar que se $y(0) \in \Delta_{n}$, entào $y(t) \in \Delta_{n}, \quad \forall l \geq 0$.

Sejam

$$
\partial \Delta_{n 1}=\left\{y \in \Delta_{n}: y_{i}=0 \text { para algum } i\right\}
$$

$\mathrm{e}$

$$
\partial \Delta_{n 2}=\left\{y \in \Delta_{n}: y_{i}=c_{i} \text { para algum } i\right\} .
$$

Sejam as normais exteriores denotadas por

$$
\eta_{i}^{1}=(0, \ldots, 0,-1,0, \ldots, 0) \text { e } \eta_{i}^{2}=(0, \ldots, 0,1,0, \ldots, 0) .
$$

( $i$-ésima posição).

É mostrado em [29] que, para qualquer conjunto compacto $C, C$ é invariante para $\frac{d x(t)}{d t}=f(x)$ se para cada ponto $y \in \partial C(\partial C$ é o bordo de $C)$, o vetor $f(y)$ é tangente ou aponta para o interior do conjunto.

Esse resultado é fácil de aplicar aqui pois $C$ é um retângulo $n$-dimensional. Logo é suficiente mostrar, para $i=1, \ldots, n$, que

$$
\left\langle\left.\frac{d y(t)}{d t}\right|_{t=0}, \eta_{i}\right\rangle \leq 0, \quad \forall y \in \partial \Delta_{n}=\partial \Delta_{n 1} \cup \partial \Delta_{n 2},
$$

onde $\eta_{i}=\eta_{i}^{1}$ se $y_{i}=0$ ou $\eta_{i}=\eta_{i}^{2}$ se $y_{i}=c_{i}$.

Como

$$
\begin{aligned}
\left\langle\left.\frac{d y(t)}{d t}\right|_{y_{i}=0}, \eta_{i}^{1}\right\rangle & =\left.\frac{d y(t)}{d t}\right|_{y_{i}=0}(0, \ldots, 0,-1,0, \ldots, 0) \\
& =\alpha_{i} y_{i}-\sum_{j=1}^{n} \beta_{j i} c_{i} y_{j}+\sum_{j=1}^{n} \beta_{j i} y_{i} y_{j}
\end{aligned}
$$




$$
\begin{aligned}
& =-\sum_{j=1}^{n} \beta_{j i} c_{i} y_{j} \leq 0 . \\
\left\langle\left.\frac{d y(t)}{d t}\right|_{y_{i}=c_{i}}, \eta_{i}^{2}\right\rangle & =\left.\frac{d y(t)}{d t}\right|_{y_{i}=c_{i}}(0, \ldots, 0,1,0, \ldots, 0) \\
& =-\alpha_{i} c_{i}+\sum_{j=1}^{n} \beta_{j i} c_{i} y_{j}-\sum_{j=1}^{n} \beta_{j i} c_{i} y_{j} \\
& =-\alpha_{i} c_{i}<0,
\end{aligned}
$$

então toda solução que começa em $\Delta_{n}$ permanece em $\Delta_{n}$.

Lema 2 Suponhamos que $G$ seja ligado. Seja $y=y(t)$ uma solução de (1.4) onde $y(0) \in \Delta_{n}$ e $y(0) \neq 0$. Então y nào está contido no d $\Delta$ para um intervalo de tempo positivo.

\section{Prova:}

Suponhamos que $y_{i}(t)=c_{i}, \quad \forall t \in\left[t_{0}, t_{1}\right]$ e algum $i$. Entào $\frac{d y_{i}(t)}{d t}=$ $0, \forall t \in\left[t_{0}, t_{1}\right]$. Além disso, de (1.4),

$$
\begin{aligned}
0=\frac{d y_{i}}{d t} & =-\alpha_{i} c_{i}+\sum_{j=1}^{n} \beta_{j i} c_{i} y_{j}-\sum_{j=1}^{n} \beta_{j i} c_{i} y_{j} \\
& =-\alpha_{i} c_{i}, \quad \forall t \in\left[t_{0}, t_{1}\right],
\end{aligned}
$$

$\operatorname{logo} \alpha_{i} c_{i}=0$ e isso é uma contradição, pois ambas quantidades sào positivas. Assim, $y_{i}$ não pode ser identicamente igual a $c_{i}$ para um intervalo de tempo positivo.

Agora suponhamos que $y_{i}(t)=0, \quad \forall t \in\left[t_{0}, t_{1}\right]$ e algum $i$.

Seja $S=\left\{i: y_{i}(t)=0, \quad \forall t \in\left[t_{0}, t_{1}\right]\right\}$ e $S^{\prime \prime}=\{1, \ldots, n\}-S$.

Como $y(t) \neq 0, \quad \forall t \in\left[t_{0}, t_{1}\right], S^{\prime}$ é não vazio, e como $i \in S$ para algum i, $S$ também é não vazio.

Logo existem $k \in S$ e $h \in S^{\prime}$ tal que $\beta_{h k} \neq 0$ (pois $G$ é ligado).

Assim, $\frac{d y_{k}}{d t}=0, \quad \forall t \in\left[t_{0}, t_{1}\right]$ e existe $T \in\left[t_{0}, t_{1}\right]$ onde $y_{h}(T) \neq 0$, logo

$$
\begin{aligned}
0=\left.\frac{d y_{k}}{d t}\right|_{t=T} & =-\alpha_{k} y_{k}(T)+\sum_{j=1}^{n} \beta_{j k} c_{k} y_{j}(T)-\sum_{j=1}^{n} \beta_{j k} y_{k}(T) y_{j}(T) \\
& =\sum_{j=1}^{n} \beta_{j k} c_{k} y_{j}(T) .
\end{aligned}
$$


Mas $\beta_{j k} y_{j} \geq 0, \quad \forall j=1, \ldots, n, \log \mathrm{o}$

$$
\left.\frac{d y_{k}}{d t}\right|_{t=T} \geq \beta_{h k} y_{h}(T)>0,
$$

e (1.8) contradiz (1.7). Então $S$ deve ser vazio e nenhum $y_{i}$ pode ser identicamente zero para um intervalo de tempo positivo.

Do Lema 2, concluímos que nenhum grupo pode ter todos os indivíduos infectados por um intervalo de tempo positivo. Além disso, nenhum grupo pode ter todos os indivíduos livres da doença por um intervalo de tempo positivo, a menos que em todos os grupos ninguém esteja infectado.

É claro que alguns grupos podem permanecer isolados, mas aqui estamos discutindo apenas grupos que se inter-relacionam sexualmente.

\subsection{Comportamento Assintótico}

Nesta seção provaremos alguns resultados sobre comportamento assintótico das soluções para uma classe de sistemas que inclui (1.4).

Teorema 1 Considere o sistema

$$
\frac{d y}{d t}=A y+N(y)
$$

onde $A$ é uma matriz $n \times n$ e $N$ é uma função de classe $\mathcal{C}^{1}$ em uma região $D \subset \mathbb{R}^{n}$. Assumimos que:

(i.) O conjunto compacto, convexo $C \subset D$ é positivamente invariante em relação ao sistema (1.9) e $0 \in C$;

(ii.) $\lim _{y \rightarrow 0} \frac{\|N(y)\|}{\|y\|}=0$;

(iii.) Existem $r>0$ e um autovetor (real) $w$ de $A^{T}$, a matriz transposta de $A$, tal que

$$
\langle w, y\rangle \geq r\|y\| \text { para todo } y \in C
$$

(iv.) $\langle w, N(y)\rangle \leq 0$ para todo $y \in C$; 
(v.) $y=0$ é o maior conjunto positivamente invariante (para (1.9)) contido em $H=\{y \in C:\langle w, N(y)>=0\}$.

Seja $\lambda \in \mathbb{R}$ o autovalor correspondente a w. Entio se $\lambda \leq 0, y=0$ é globalmente assintoticamente estável em $C$. Se $\lambda>0$, para qualquer $y_{0} \in$ $C-\{0\}$ a solução $\phi\left(t, y_{0}\right)$ de (1.9) satisfaz

$\liminf _{t \rightarrow \infty}\left\|\phi\left(t, y_{0}\right)\right\| \geq m$, onde $m>0$. independe de $y_{0}$. Além disso, existe uma solução constante de (1.9), $y=k, k \in C-\{0\}$.

\section{Demonstração:}

Seja $V: \mathbb{R}^{n} \rightarrow \mathbb{R}$ dada por $V(y)=\langle w, y\rangle$. Então $V$ é positiva $\mathrm{e}$ definida em $C$ e

$$
\begin{aligned}
V^{\prime}(y)=\left\langle w, \frac{d y}{d t}\right\rangle & =\langle w, A y\rangle+\langle w, N(y)\rangle \\
& =\left\langle A^{T} w, y\right\rangle+\langle w, N(y)\rangle \\
& =\lambda\langle w, y\rangle+\langle w, N(y)\rangle .
\end{aligned}
$$

Suponhamos primeiro que $\lambda \leq 0$. Então $V^{\prime}(y) \leq 0 \mathrm{em} C$.

Seja $M=\left\{y \in C: V^{\prime}(y)=0\right\}$. Como $M \subset H$, segue da hipótese $(v)$ que $y=0$ é o maior conjunto invariante contido em $M$.

Então pelo Corolário 4 do Apêndice, $y=0$ é globalmente assintoticamente estável em $C$.

Suponhamos agora que $\lambda>0$. Para $\varepsilon>0$ sejam

$$
C_{V=\varepsilon}=\{y \in C: V(y)=\varepsilon\} \text { e } C_{V \geq \varepsilon}=\{y \in C: V(y) \geq \varepsilon\} .
$$

Notemos que $C_{V \geq \varepsilon}$ é convexo e pela hipótese (iii) é não vazio para $\varepsilon>0$ suficientemente pequeno.

Afirmamos que existe um $\varepsilon_{0}>0$ tal que para $0<\varepsilon<\varepsilon_{0}, C_{V \geq \varepsilon}$ é positivamente invariante em relação ao sistema (1.9). Então como $C_{V \geq \varepsilon}$ é um conjunto compacto e convexo se $\varepsilon<\varepsilon_{0}$, o Lema 7 do Apêndice implica que (1.9) deve ter uma solução constante $k \in C_{V \geq \varepsilon}$ e $k \neq 0$, pois $0 \notin C_{V \geq \varepsilon}$.

Para ver que $\varepsilon_{0}$ realmente existe, vamos primeiro mostrar que existe um $\varepsilon_{0}>0$ tal que para $\varepsilon \in\left(0, \varepsilon_{0}\right], V^{\prime}(y)>0$ para $y \in C_{V=\varepsilon}$.

Como

$$
|<w, N(y)>| \leq\|w\|\|N(y)\|
$$

temos 


$$
-\|w\|\|N(y)\| \leq\langle w \cdot N(y)\rangle \leq\|w\|\|N(y)\|
$$

assim da igualdade (1.10), para $\varepsilon>0$

$$
V^{\prime}(y) \geq \lambda \varepsilon-\|w\|\|N(y)\| \text { para } y \in C_{V=\varepsilon} .
$$

Escolheremos agora $\delta>0$ tal que $\lambda-\frac{\|w\|}{r} \delta>0$ (o que é sempre possível, pois $\lambda>0$ e $r>0$ ).

Tomemos $\varepsilon_{0}>0$ tal que $\|N(y)\| \leq \delta\|y\|$ para $\|y\| \leq \frac{\varepsilon_{0}}{r}$. A condição (iii) implica que para $y \in C_{V=\varepsilon}$ temos $\|y\| \leq \frac{\varepsilon}{r}$.

Entào por (1.11) e para $y \in C_{V=s}$ segue que

$$
V^{\prime}(y) \geq \lambda \varepsilon-\|w\| \frac{\delta \varepsilon}{r}=\left(\lambda-\frac{\|w\|}{r} \delta\right) \varepsilon>0 \text { para } \varepsilon \in\left(0, \varepsilon_{0}\right] .
$$

Portanto se $y \in C, y \neq 0$ e $V(y)=\varepsilon, \varepsilon \in\left(0, \varepsilon_{0}\right]$, entào $V(y(t)) \geq \varepsilon, \forall t \geq 0$, pois se não existem $\bar{t} \geq 0$ e $\delta>0$ tal que $V(y(\bar{t}))=\varepsilon$ e $V(y(s))<\varepsilon_{0}$ para $s \in[\bar{t}, \bar{t}+\delta]$. Isto não pode ocorrer pois $V^{\prime}(\phi(s, x))>0$, doncle concluímos que $C_{V \geq \varepsilon}$ é positivamente invariante.

Seja $y \in C, y \neq 0$ e $V(y) \leq \varepsilon_{0}$. De (1.12) temos $V^{\prime}(y)>0$. Vamos mostrar que:

$$
\liminf _{t \rightarrow \infty} V(\phi(t, x)) \geq \varepsilon_{0}, \quad \forall x \in C, \quad x \neq 0 .
$$

De fato:

Afirmação 1

$$
\text { Existe } \xi \geq 0 \text { tal que } V(\phi(\xi, x)) \geq \varepsilon_{0} \text {. }
$$

Se $V(x) \geq \varepsilon_{0}$ não há nada a fazer. Suponhamos que $V(\phi(t, x))<$ $\varepsilon_{0}, \quad \forall t \geq 0$.

Segue de $(1.12)$ que $V^{\prime}(\phi(t, x))>0, \quad \forall t \geq 0$.

Portanto $V(\phi(t, x))$ é crescente. Logo $V^{\prime}(\phi(t, x))>\mu>0$ e entào

$$
V(\phi(t, x)) \geq V(x)+\mu(t-0) \stackrel{t \rightarrow \infty}{\longrightarrow} \infty \text {. Contradição. }
$$




\section{Afirmaçào 2}

$$
V(\phi(t, x)) \geq \varepsilon_{0}, \quad \forall t \geq \xi
$$

Segue imediatamente do fato de $C_{V \geq \varepsilon}$ ser positivamente invariante.

Da Afirmação 2 o resultado acima segue imediatamente.

Seja $m=\inf \left\{\|y\|: V(y) \geq \varepsilon_{0}\right\}$. Entào $m>0 \mathrm{e}$

$$
\liminf _{t \rightarrow \infty}\|\phi(t, y)\| \geq m \text { para todo } y \in C, \quad y \neq 0 .
$$

Investigaremos agora o comportamento assintótico das soluçòes de (1.4).

Sabemos que $y=0$ é uma solução constante. Provaremos que ou $y=0$ é globalmente assintoticamente estável em $\Delta_{n}$, ou, se este não é o caso, existe outra solução constante $k \in \Delta_{n}-\{0\}$ e $y=k$ é globalmente assintoticamente estável em $\Delta_{n}-\{0\}$.

Seja $y=\left(y_{1}, y_{2}, \ldots, y_{n}\right)^{T}$ e seja $A=\left(a_{i j}\right)$ a matriz definida por $a_{i j}=\beta_{j i} c_{i}$ quando $i \neq j$ e $a_{i i}=\beta_{i i} c_{i}-\alpha_{i}$.

Nossa hipótese que $G$ é ligado é equivalente a assumir que $A$ é irredutivel.

Seja $N(y)$ um vetor coluna cuja $i$-ésima componente é $-\sum_{j=1}^{n} \beta_{j i} y_{i} y_{j}$.

Entào (1.4) pode ser escrita

$$
\frac{d y}{d t}=A y+N(y)
$$

Seja $s(A)=\max _{1 \leq i \leq n} R e \lambda_{i}$, onde $\lambda_{i}$ são os autovalores de $A$, para $i=1, \ldots, n$ e Re denota a parte real. Então temos o seguinte resultado para o sistema (1.13). Assumimos que $G$ é ligado (ou equivalentemente $A$ é irredutivel).

Teorema 2 Para o sistema (1.13) exitem duas possibilidades. Ou $s(A) \leq$ 0 e entào $y=0$ é globalmente assintoticamente estável em $\Delta_{n}$, ou $s(A)>0$ $e$ então existe uma solução constante $k \in \Delta_{n}-\{0\}$ tal que $k$ é globalmente assintoticamente estável em $\Delta_{n}-\{0\}$.

Demonstração: A condição (i) do Teorema 1 é satisfeita tomando-se $C=\Delta_{n}$. A condição (ii) está satisfeita. Para a condição (iii), notemos que 
$A^{T}$ é irredutivel se e somente se $A$ é irredutivel. Seja $w=\left(w_{1}, \ldots, w_{n}\right)$ o autovetor de $A^{T}$ dado pelo Corolário 3 do Apêndice e seja

$$
u_{0}=\min _{1 \leq i \leq n} w_{i}>0 .
$$

Para $y \in \Delta_{n}$, temos que

$$
<w, y\rangle \geq w_{0} \sum_{i=1}^{n} y_{i} \geq w_{0}\left(\sum_{i=1}^{n} y_{i}^{2}\right)^{(1 / 2)} .
$$

Assim,

$$
<w, y>\geq r\|y\|, \quad \forall y \in \Delta_{n} \text {, onde } r=w_{0} .
$$

A condição $(i v)$ é satisfeita tomando-se o vetor $w$ como enunciado no item (iii) acima.

Para verificar $(v)$ seja $H=\left\{y \in \Delta_{n}:\langle u, N(y)>=0\}\right.$.

Se $y \in H$, então

$$
\sum_{j=1}^{n} \beta_{j i} y_{j} y_{i} w_{i}=0, \quad \forall i=1, \ldots, n
$$

mas cada termo da soma é não negativo, portanto

$$
\beta_{j i} y_{j} y_{i} w_{i}=0, \quad \forall i, j .
$$

Suponhamos $y \neq 0$. Então podemos escolher $h$ tal que $y_{h} \neq 0$, logo como $w>0$,

$$
\beta_{h i} y_{i}=0 . \quad \forall i .
$$

Como $G$ é ligado, existe algum $k$ tal que $3_{h k} \neq 0$, logo $y_{k}=0$.

Assim, se $y \in H$, então $y \in \partial \Delta_{n}$. Conseqüentemente, pelo Lema 2, o único conjunto invariante em relação a (1.13) contido em $H$ é $y=0$ e portanto a condição $(v)$ está satisfeita.

Portanto todas as hipóteses do Teorema 1 estão satisfeitas, além disso, observemos que se $\lambda \in \mathbb{R}$ é o autovalor da matriz $A^{T}$ dado pelo Corolário 3 do Apêndice temos que $\lambda=s\left(A^{T}\right)=s(A)$ e entào ou $s(A) \leq 0$ e a origem é globalmente assintoticamente estável em $\Delta_{n}$, ou $s(A)>0$ e existe uma solução constante de (1.13), $y=k \in \triangle_{n}-\{0\}$.

Provaremos agora que $y=k$ é globalmente assintoticamente estável em $\Delta_{n}-\{0\}$. 
Primeiro provaremos que quando $s(A)>0, y=0$ e $y=k$ sào as únicas soluções constantes em $\Delta_{n}$. Suponhamos que $y=k$ e $y=h$ sào duas soluções constantes de (1.13), ambas diferentes de zero. Se $k \neq h$, entào para algum $i, k_{i} \neq h_{i}$. Assumiremos sem perda de generalidade que $h_{1}>k_{1}$ e além disso que $\frac{h_{1}}{k_{1}} \geq \frac{h_{i}}{k_{i}}, \forall i$. (Lema 2 implica que $k>0$, isto é, $k_{i}>0, \forall i$.)

Logo, como $h$ e $k$ são soluçòes constantes, temos

$$
\begin{aligned}
0 & =-\alpha_{1} h_{1}+\left(c_{1}-h_{1}\right) \sum_{j=1}^{n} 3_{j 1} h_{j} \\
& =-\alpha_{1} k_{1}+\left(c_{1}-k_{1}\right) \sum_{j=1}^{n} 3_{j 1} k_{j} .
\end{aligned}
$$

Assim

$$
\begin{aligned}
0 & =-\alpha_{1} k_{1}+\left(c_{1}-h_{1}\right) \sum_{j=1}^{n} 3_{j 1} h_{j} \frac{k_{1}}{h_{1}} \\
& =-\alpha_{1} k_{1}+\left(c_{1}-k_{1}\right) \sum_{j=1}^{n} \beta_{j 1} k_{j} .
\end{aligned}
$$

Mas $h_{i} \frac{k_{1}}{h_{1}} \leq k_{i}$ e $0<c_{1}-h_{1}<c_{1}-k_{1}$. Portanto de (1.14) obtemos a seguinte desigualdade,

$$
\begin{aligned}
0 & =-\alpha_{1} k_{1}+\left(c_{1}-h_{1}\right) \sum_{j=1}^{n} \beta_{j 1} h_{j} \frac{k_{1}}{h_{1}} \\
& <-\alpha_{1} k_{1}+\left(c_{1}-k_{1}\right) \sum_{j=1}^{n} \beta_{j 1} k_{j}=0 .
\end{aligned}
$$

Isso é uma contradição, logo existe uma única solução constante de (1.13), $y=\left(k_{1}, \ldots, k_{n}\right) \in \Delta_{n}-\{0\}$.

A fim de verificar o comportamento assintótico das soluções de (1.13) em $\Delta_{n}$, definimos as seguintes funções :

$\mathrm{e}$

$$
M: \Delta_{n} \rightarrow \mathbb{R} \text {, onde } M(y)=\max _{1 \leq i \leq n} \frac{y_{i}}{k_{i}}
$$

$$
m: \Delta_{n} \rightarrow \mathbb{R} \text {, onde } m(y)=\min _{1 \leq i \leq n} \frac{y_{i}}{k_{i}}
$$

$M$ e $m$ são contínuas e a derivada lateral à direita de ambas existe ao longo das soluções. 
Se $y=y(t)$ é uma soluçào de (1.13), entào reordenando as coordenadas se necessário, podemos assumir. para um dado $t_{0} \mathrm{e} \Xi>0$ suficientemente pequeno, que

$$
M(y(t))=\frac{y_{1}(t)}{k_{1}}, \quad \forall t \in\left[t_{0}, t_{0}+\Xi\right]
$$

Então

$$
M_{(1.13)}^{\prime}\left(y\left(t_{0}\right)\right)=\frac{d M\left(y\left(t_{0}\right)\right)}{d t}=\frac{y_{1}^{\prime}\left(t_{0}\right)}{k_{1}},
$$

onde $y$ é solução de (1.13). De (1.4) obtemos

$$
k_{1} \frac{y_{1}^{\prime}\left(t_{0}\right)}{y_{1}\left(t_{0}\right)}=-\alpha_{1} k_{1}+\left(c_{1}-y_{1}\left(t_{0}\right)\right) \sum_{j=1}^{n} 3_{j 1} \frac{k_{1} y_{j}\left(t_{0}\right)}{y_{1}\left(t_{0}\right)} .
$$

Então se $M\left(y\left(t_{0}\right)\right)>1$, por $(1.15)$ temos

$$
k_{1} \frac{y_{1}^{\prime}\left(t_{0}\right)}{y_{1}\left(t_{0}\right)}<-\alpha_{1} k_{1}+\left(c_{1}-k_{1}\right) \sum_{j=1}^{n} \beta_{j 1} k_{j}=0
$$

como $k_{1}>0$ e $y_{1}\left(t_{0}\right)>0$, concluímos que $y_{1}^{\prime}\left(t_{0}\right)<0$. Assim se $M\left(y\left(t_{0}\right)\right)>1$,

$$
M_{(1.13)}^{\prime}\left(y\left(t_{0}\right)\right)=\limsup _{h \rightarrow 0^{+}} \frac{M\left(y\left(t_{0}+h\right)\right)-M\left(y\left(t_{0}\right)\right)}{h}<0 .
$$

Analogamente podemos provar que se

$$
M\left(y\left(t_{0}\right)\right)=1 \text { então } M_{(1.13)}^{\prime}\left(y\left(t_{0}\right)\right) \leq 0,
$$

se

$$
0<m\left(y\left(t_{0}\right)\right)<1 \text { então } m_{(1.13)}^{\prime}\left(y\left(t_{0}\right)\right)>0
$$

e se

$$
m\left(y\left(t_{0}\right)\right)=1 \text { então } m_{(1.13)}^{\prime}\left(y\left(t_{0}\right)\right) \geq 0 .
$$

Notemos que se $m\left(y\left(t_{0}\right)\right)=0$ então existe $i \in\{1, \ldots, n\}$ tal que $\frac{y_{i}\left(t_{0}\right)}{k_{i}}=$ 0 , portanto $y_{i}\left(t_{0}\right)=0$. Assim

$$
\begin{aligned}
\frac{d y_{i}\left(t_{0}\right)}{d t} & =-\alpha_{i} y_{i}\left(t_{0}\right)+\sum_{j=1}^{n} \beta_{j i} c_{i} y_{j}\left(t_{0}\right)-\sum_{j=1}^{n} \beta_{j i} y_{i}\left(t_{0}\right) y_{j}\left(t_{0}\right) \\
& =\sum_{j=1}^{n} \beta_{j i} c_{i} y_{j}\left(t_{0}\right) \geq 0 .
\end{aligned}
$$


Logo se $m\left(y\left(t_{0}\right)\right)=0$, entào $m^{\prime}\left(y\left(t_{0}\right)\right) \geq 0$.

Sejam

$$
V: \Delta_{n} \rightarrow \mathbb{R} \text {, onde } V(y)=\max \{M(y)-1,0\} .
$$

$\mathrm{e}$

$$
W: \Delta_{n} \rightarrow \mathbb{R} \text {, onde } W(y)=\max \{1-m(y), 0\} .
$$

Ambas funções são não negativas e contínuas. Notemos que

$$
V_{(1.13)}^{\prime}(y) \leq 0 \text { e } W_{(1.13)}^{\prime}(y) \leq 0 .
$$

Sejam

$$
H_{V}=\left\{y \in \Delta_{n}: V_{(1.13)}^{\prime}(y)=0\right\} \text { e } H_{W}=\left\{y \in \Delta_{n}: W_{(1.13)}^{\prime}(y)=0\right\} .
$$

Entào

$$
H_{V}=\left\{y \in \Delta_{n}: 0 \leq y_{i} \leq k_{i}, i=1, \ldots, n\right\}
$$

e

$$
H_{W}=\left\{y \in \Delta_{n}: k_{i} \leq y_{i} \leq c_{i}, i=1, \ldots, n\right\} \cup\{0\} .
$$

Assim pelo Teorema 9 do Apêndice, qualquer solução de (1.13) começando em $\Delta_{n}$ se aproximará de $H_{V} \cap H_{W}=\{k\} \cup\{0\}$, mas se $y(t) \neq 0, \forall t \geq 0$, pelo Teorema 1 sabemos que $\liminf _{t \rightarrow \infty}\|y(t)\| \geq m>0$, então concluímos que qualquer solução $y$ de (1.13) tal que $y(0) \in \Delta_{n}-\{0\}$, satisfaz $\lim _{t \rightarrow \infty} y(t)=k$.

Provaremos abaixo que a solução $y=k$ é estável em $\Delta_{n}$ e assim $y=k$ é globalmente assintoticamente estável em $\Delta_{n}-\{0\}$.

Seja $V_{s}$ a vizinhança de $k$, dada por

$$
V_{\varepsilon}=\left\{y \in \mathbb{R}^{n}: M(y) \leq 1+\varepsilon \mathrm{e} m(y) \geq 1-\varepsilon\right\} .
$$

Afirmação 1

Se $y_{0}=y\left(t_{0}\right) \in V_{\text {s }}$ então $y(t) \in V_{\varepsilon}, \quad \forall t \geq t_{0}$, onde $y$ é solução de (1.13).

Seja $\bar{t}=\left\{\sup t \geq t_{0}: y(s) \in V_{s}, \forall t_{0} \leq s \leq t\right\}$. Suponhamos que $\bar{t}$ seja finito. Entào é claro que $y(\bar{t}) \in \partial \Delta$. Logo

$$
M(y(\bar{t}))=1+\varepsilon \text { ou } m(y(\bar{t}))=1-\varepsilon .
$$

Suponhamos que $M(y(\bar{t}))=1+\varepsilon$ (o outro caso é idêntico). Então

$$
M^{\prime}(y(\bar{t}))<0
$$


e portanto existe $\delta>0$ tal que

$$
M(y(\bar{t}))=1+\varepsilon>M(y(\bar{t}+s))>1-\varepsilon . \forall 0<s \leq \delta .
$$

Logo

$$
y(\bar{t}+s) \in V_{\varepsilon} \text {. Contradiçào . }
$$

Afirmação 2

Dado $\varepsilon>0$, existe $\varepsilon_{1}>0$ tal que $V_{s_{1}} \subset U_{\varepsilon}=\left\{y \in \mathbb{R}^{n}:\|k-y\|_{2} \leq \varepsilon\right\}$.

Seja $y \in V_{\varepsilon_{1}}$, onde $\varepsilon_{1}=\frac{\varepsilon \sqrt{n}}{2 n K}$ e $K=\max _{1 \leq i \leq n} k_{i}$, então

$$
1-\varepsilon_{1} \leq \frac{y_{i}}{k_{i}} \leq 1+\varepsilon_{1},
$$

$\operatorname{mas} \varepsilon_{1}=\frac{\varepsilon \sqrt{n}}{2 n \kappa^{\prime}}$, então

$$
1-\frac{\varepsilon \sqrt{n}}{2 n K^{*}} \leq \frac{y_{i}}{k_{i}} \leq 1+\frac{\varepsilon \sqrt{n}}{2 n K^{*}}
$$

multiplicando-se ambas desigualdades por $k_{i}>0$. temos

$$
k_{i}-k_{i} \frac{\varepsilon \sqrt{n}}{2 n K} \leq y_{i} \leq k_{i}+k_{i} \frac{\varepsilon \sqrt{n}}{2 n K^{-}}
$$

subtraindo-se $k_{i}$ e observando-se que $\frac{k_{i}}{K} \leq 1$, temos

$$
-\frac{\varepsilon \sqrt{n}}{2 n} \leq-k_{i} \frac{\varepsilon \sqrt{n}}{2 n K} \leq y_{i}-k_{i} \leq k_{i} \frac{\varepsilon \sqrt{n}}{2 n K^{\prime}} \leq \frac{\varepsilon \sqrt{n}}{2 n} \text {. }
$$

Logo

$$
y_{i} \in\left[k_{i}-\frac{\varepsilon \sqrt{n}}{2 n}, k_{i}+\frac{\varepsilon \sqrt{n}}{2 n}\right] \text {, }
$$

isto é,

$$
\|y-k\|_{\infty} \leq \frac{\varepsilon \sqrt{n}}{2 n} \text {, e então }\|y-k\|_{2} \leq \varepsilon, \text { pois }\|y-k\|_{2} \leq \sqrt{n}\|y-k\|_{\infty} \text {. }
$$

Portanto $y \in U_{\varepsilon}$. 
Do Teorema 2 obtemos então os seguintes resultados: ou a epidemia extingue-se naturalmente para todo estágio inicial possivel, ou então isto não é verdade e se o número inicial de infectivos de pelo menos um grupo não é zero, a doença permanecerá endêmica para todo tempo futuro.

Além disso, o número de infectivos e suscetíveis de cada grupo se aproximará de um nível constante positivo, que é independente dos níveis iniciais.

Exemplo 1 É interessante considerar uma situaçào particular para $n=2$ com a hipótese adicional de que não exista interaçào dentro de cada grupo.

Assumiremos que existe um grupo de machos e um grupo de fêmeas e que cada grupo interage somente com o outro, isto é, assumimos que não ocorrem. contatos homossexuais.

Neste caso A será uma matriz $2 \times 2$ com tr.A<0, $\operatorname{assim} s(A) \leq 0$ se e somente se $\operatorname{det} A \geq 0$. 1.

Como det $A=\alpha_{1} \alpha_{2}-\beta_{12} c_{2} \beta_{21} c_{1}, s(A) \leq 0$ se e somente se $\frac{\beta_{21} c_{1}}{\alpha_{2}} \frac{\beta_{12} c_{2}}{\alpha_{1}} \leq$

Notemos que $\frac{1}{\alpha_{1}}$ é o periodo médio de infecciosidade das fêmeas e $\frac{1}{\alpha_{2}}$ é o periodo médio de infecciosidade dos machos. Entào $\frac{\beta_{21} x_{1}}{\alpha_{2}}$ é igual à média do número de fêmeas que um macho infectivo contacta durante seu período de infeç̧ão.

O máximo desta média ocorre para $x_{1}=c_{1}$, quando toda fêmea é suscetível $e \frac{\beta_{12} x_{2}}{\alpha_{1}}$ é a média do número de machos que uma fêmea infectiva contacta durante seu periodo de infecção, que é $\frac{\beta_{12} c_{2}}{\alpha_{1}}$ quando todo macho é suscetível. Chamamos a quantidade $\frac{\beta_{21} c_{1}}{\alpha_{2}}$ de taxa de contato máxima do macho $e$ $\frac{\beta_{12} c_{2}}{\alpha_{1}}$ de taxa contato máxima da fêmea.

Dessa maneira, temos como caso particular que quando o produto da taxa de contato máxima do macho com taxa de contato máxima da fêmea é menor ou igual a um, a epidemia se extinguirá em cada grupo. Por outro lado, quando esse produto é maior que um a doença permanecerá endêmica e os níveis de infectivos e suscetíveis de cada grupo se aprorimarào de valores constantes e positivos. 


\section{Capítulo 2}

\section{Um Modelo de Transmissão de Doença em Uma População Não Constante}

\subsection{Preliminares}

Neste capítulo estudaremos um modelo geral de transmissão de doença supondo que o tamanho da população varia e a imunidade conferida à pessoa é somente temporária, sendo assim. trataremos de uma doença que normalmente permanece endêmica.

Além disso, vamos supor também que a classe dos recuperados possa ser reinfectada diretamente, ou seja, a imunidade além de temporária é apenas parcial.

A hipótese de que a classe dos recuperados possa também ser suscetível se aplica a doenças tais com a influenza, onde a infecção causada por uma cepa garante alguma imunidade temporária contra infecções de cepas do mesmo grupo.

Para abordar este problema usaremos um modelo do tipo SI RS com taxa de inciclência nào linear.

Este trabalho é baseado em um artigo de W. R. Derrick e P. van den Driessche (1993)[7]. 


\subsection{Um Modelo Geral SIRS}

O comportamento de um modelo epidemiológico SIRS em uma população variando de tamanho será modelado por um sistema de equaçòes diferenciais em $\mathbb{R}_{+}^{3}$.

Aqui $S$ é o número de indivíduos suscetíveis, $I$ é o número de indivíduos infectivos, $R$ é o número de indivíduos recuperados (ou removidos) na população e $N=S^{\prime}+I+R$ é o número total da população.

Nascimentos e mortes naturais são assumidos como senclo proporcionais ao número de indivíduos em cada classe, sendo que todo recém-nascido é considerado suscetível. Mortes adicionais devido à doença podem ocorrer nas classes dos infectivos e dos recuperados.

A taxa com que suscetíveis se tornam infectivos é dada por uma função incidência $I \Phi(S, I, N)$ não linear. Indivíduos recuperados perdem a imunidade e novamente se tornam suscetíveis podendo também ser reinfectados diretamente a uma taxa $I \Psi(R, I, N)$.

Usaremos os seguintes parâmetros que são assumidos como sendo não negativos, a não ser quando especificados:

$b=$ taxa per capita de nascimento,

$d=$ taxa per capita de morte natural,

$\varepsilon=$ taxa adicional per capita de morte dos infectivos,

$\delta=$ taxa adicional per capita de morte dos recuperados,

$\gamma=$ taxa per capita de recuperaçào dos infectivos,

$\rho=$ taxa per capita de perda de imunidade dos recuperados.

Faremos as seguintes hipóteses neste modelo:

(i.) A incidência de doença na classe dos suscetiveis é dada pela função $I \Phi(S, I, N)$, onde $\Phi(S, I, N)$ é não negativa, limitada, de classe $\mathcal{C}^{1}$ e homogênea de grau zero em $\mathbb{R}_{+}^{3}$. Assumimos também que:

$$
\begin{gathered}
\lim _{S \rightarrow 0^{+}} \Phi(S, I . N)=0, \\
\limsup _{I \rightarrow 0^{+}} \Phi(S, I, N)=0 \text { e } \quad \limsup _{N \rightarrow 0^{+}} \Phi(S, I, N)=\Phi_{0} \geq 0 .
\end{gathered}
$$

(ii.) A classe dos recuperados pode ser reinfectada diretamente com uma taxa de transferência $I \Psi(R, I, N)$, onde $\Psi(R, I, N)$ é também não negativa, limitada, de classe $\mathcal{C}^{1}$ e homogênea de grau zero em $\mathbb{R}_{+}^{3}$. 
Assumimos também que:

$$
\begin{gathered}
\lim _{R \rightarrow 0^{+}} \Psi(R, I, N)=0 . \\
\limsup _{I \rightarrow 0^{+}} \Psi(R, I, N) \text { e } \limsup _{N \rightarrow 0^{+}} \Psi(R . I, N)=\Psi_{0}
\end{gathered}
$$

são nào negativos e limitados.

Nosso modelo é esquematizado na. Fig. 2.1.

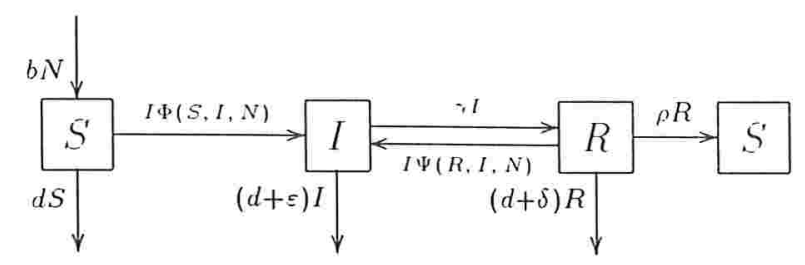

Fig. 2.1 Diagrama de fluxos para o modelo SIRS.

As hipóteses acima resultam no seguinte sistema de equações diferenciais, onde a derivada $\frac{d}{d t}$ é denotada por ' :

$$
\left\{\begin{array}{l}
S^{\prime}=b N-d S+\rho R-I \Phi(S, I, N), \\
I^{\prime}=I[\Phi(S, I, N)+\Psi(R, I, N)-(d+\varepsilon+\gamma)], \\
R^{\prime}=\gamma I-(d+\delta+\rho) R-I \Psi(R, I, N),
\end{array}\right.
$$

ou, em forma de matriz, por:

$$
\begin{aligned}
{\left[\begin{array}{c}
S \\
I \\
R
\end{array}\right]^{\prime}=} & {\left[\begin{array}{ccc}
b-d & b & b+\rho \\
0 & -(d+\varepsilon+\gamma) & 0 \\
0 & \gamma & -(d+\delta+\rho)
\end{array}\right]\left[\begin{array}{l}
S \\
I \\
R
\end{array}\right]+} \\
& +\left[\begin{array}{c}
I \Phi(S, I, N)+I \Psi(S, I, N) \\
I \Psi(R, I, N)
\end{array}\right]
\end{aligned}
$$

Observemos que esta equação matricial é da forma $\boldsymbol{x}^{\prime}=\boldsymbol{M} \boldsymbol{x}+\boldsymbol{f}(\boldsymbol{x})$, onde $\boldsymbol{x}=(S, I, R)^{T}, \boldsymbol{M}$ é uma matriz $3 \times 3$ essencialmente não negativa, isto é, é uma matriz tal que os elementos fora da diagonal principal são não negativos e pelo menos um desses elementos é positivo. $f: \mathbb{R}_{+}^{3} \rightarrow \mathbb{R}_{+}^{3}$ é uma função de classe $\mathcal{C}^{1}$ e homogênea de grau 1, isto é, $\boldsymbol{f}(a \boldsymbol{x})=a \boldsymbol{f}(\boldsymbol{x})$, para $a>0$. 
A equaçào para a população total $N$ é obtida somando-se (2.1)-(2.3):

$$
N^{\prime}=(b-d) N-\varepsilon I-\delta R .
$$

O modelo (2.1)-(2.4) é bem posto no sentido de que dados iniciais não negativos $(S, I, R)$ conduzem a soluções não negativas que estão definidas para qualquer $t \geq 0$, pois:

$$
b N+\rho R \geq I \lim _{S \rightarrow 0^{+}} \Phi(S, I, N)=0 \quad \text { e } \quad \gamma \geq \lim _{R \rightarrow 0^{+}} \Psi(R, I, N)=0
$$

e então quando $S \rightarrow 0^{+}$em $(2.1)$ e usando a primeira desigualdade em (2.5), resulta que $S^{\prime} \geq 0$, de modo que o plano $I R$ é uma barreira para as trajetórias.

Similarmente, quando $I \rightarrow 0^{+}$em (2.2), resulta que $I^{\prime}=0$ e quando $R \rightarrow 0^{+}$em (2.3) e aplicando a segunda desigualdade em (2.5) resulta que $R^{\prime} \geq 0$. Assim, todas trajetórias permanecem em $\mathbb{R}_{+}^{3}$.

Ao procurarmos os pontos de equilíbrio de (2.1)-(2.4), observaremos que $I=0$ implica que $R=0$ de modo que $b N=d S$. Se $b=d$ então qualquer $(N, 0,0)$ é um ponto de equilíbrio, mas se $b \neq d$ então a origem é o único ponto de equilíbrio $\operatorname{com} I=0$.

Se $I \neq 0, b=d$ e $\varepsilon=\delta=0$ então a curva satisfazendo

$$
\Phi(S, I, N)+\Psi(R, I, N)=b+\gamma \quad \text { e }(\gamma-\Psi(R, I, N)) I=(b+\rho) R
$$

consiste de pontos de equilíbrio, pois (2.6) implica que o lado direito das equações (2.1)-(2.3) é zero, pois $N=S+I+R$.

Nesse caso não há excesso de morte devido à doença e as taxas populacionais de nascimento e morte são iguais, assim, a população total permanece constante. Como estamos interessados no caso em que a população varia de tamanho, assumimos que $b \neq d$.

\subsection{Não Existência de Soluções Periódicas}

Estamos interessados em estudar situações onde a população $N(t)$ não é estacionária. Para tanto consideraremos as proporções de indivíduos nas três classes epidemiológicas,

$$
s=S / N, \quad i=I / N, \text { e } r=R / N
$$


e examinaremos a dinâmica do sistema resultante no conjunto

$$
\mathcal{D}=\left\{(s, i, r) \in \mathbb{R}^{3}+s+i+r=1\right\}
$$

Com essas variáveis, o sistema (2.1)-(2.3) se torna

$$
\left\{\begin{array}{l}
s^{\prime}=b(1-s)+\rho r+\varepsilon s i+\delta s r-i \Phi(s, i), \\
i^{\prime}=-(b+\varepsilon+\gamma) i+\varepsilon i^{2}+\delta i r+i \Phi(s, i)+i \Psi(r, i), \\
r^{\prime}=\gamma i-(b+\delta+\rho) r+\varepsilon i r+\delta r^{2}-i \Psi(r, i),
\end{array}\right.
$$

onde

$$
\Phi(s, i)=\Phi(s, i, 1)=\Phi(S / N, I / N, N / N)=\Phi(S, I, N)
$$

$\mathrm{e}$

$$
\Psi(r, i)=\Psi(r, i, 1)=\Psi(R / N, I / N, N / N)=\Psi(R, I, N)
$$

por homogeneidade. Reescrevendo (2.8)-(2.10) em forma de matriz e lembrando que $1-s=i+r$ temos

$$
\begin{aligned}
{\left[\begin{array}{l}
s \\
i \\
r
\end{array}\right]^{\prime}=} & {\left[\begin{array}{ccc}
0 & b & b+\rho \\
0 & -(b+\varepsilon+\gamma) & 0 \\
0 & \gamma & -(b+\delta+\rho)
\end{array}\right]\left[\begin{array}{c}
s \\
i \\
r
\end{array}\right]+(\varepsilon i+\delta r)\left[\begin{array}{c}
s \\
i \\
r
\end{array}\right]+} \\
& +\left[\begin{array}{c}
-i \Phi(s, i) \\
i \Phi(s, i)+i \Psi(r, i) \\
-i \Psi(r, i)
\end{array}\right]
\end{aligned}
$$

Procuramos condições para a existência e estabilidade de pontos de equilíbrio e a existência ou não de soluções periódicas e polígonos de fase para este modelo. (Uma curva fechada conectando vários pontos de equilíbrio cujos segmentos entre sucessivos pontos de equilíbrio são trajetórias de soluções de um sistema de equações diferenciais é chamado de polígono de fase. Ver [10].)

Um polígono de fase cujos lados são trajetórias de mesmo sentido é chamado de polígono de fase orientado.

Não é difícil ver que o sistema (2.11) tem a forma

$$
\boldsymbol{y}^{\prime}=\boldsymbol{F}(\boldsymbol{y})=M \boldsymbol{y}-<\mathbf{1}, M \boldsymbol{y}>\boldsymbol{y}+\boldsymbol{f}(\boldsymbol{y}),
$$


onde $\boldsymbol{y}=(s, i, r)^{T}, \mathbf{1}=(1,1.1)^{T},<\mathbf{1}, \boldsymbol{f}(\boldsymbol{y})>=0 \mathrm{e}$

$$
M=\left[\begin{array}{ccc}
b-d & b & b+\rho \\
0 & -(d+\varepsilon+\gamma) & 0 \\
0 & \gamma & -(d+\delta+\rho)
\end{array}\right]
$$

é uma matriz essencialmente não negativa como definido na seção anterior.

O hiperplano $\langle\mathbf{1}, \boldsymbol{y}\rangle=1$ é invariante para o fluxo (2.12) pois

$$
<\mathbf{1}, \boldsymbol{y}\rangle^{\prime}=<1 . M y>(1-<\mathbf{1}, \boldsymbol{y}>)+<\mathbf{1}, \boldsymbol{f}(\boldsymbol{y})>=0 .
$$

Provaremos que o sistema (2.12) não tem órbitas fechadas, homoclínicas ou polígonos de fase orientada.

Seja $\boldsymbol{g}=\alpha \boldsymbol{y} \times \boldsymbol{F}(\boldsymbol{y})$, onde $\alpha=\left(y_{1} y_{2} y_{3}\right)^{-1}$. Então, como $\boldsymbol{y} \times \boldsymbol{y}=0$, temos que

$$
\begin{aligned}
\boldsymbol{g} & =\alpha \boldsymbol{y} \times[\boldsymbol{M} \boldsymbol{y}-<\mathbf{1}, \boldsymbol{M} \boldsymbol{y}>\boldsymbol{y}+\boldsymbol{f}(\boldsymbol{y})] \\
& =\alpha \boldsymbol{y} \times \boldsymbol{M} \boldsymbol{y}+\alpha \boldsymbol{y} \times \boldsymbol{f}(\boldsymbol{y}) \\
& =\boldsymbol{g}_{\boldsymbol{M}}+\boldsymbol{g}_{\boldsymbol{f}},
\end{aligned}
$$

onde $\boldsymbol{g}_{\boldsymbol{M}}=\alpha \boldsymbol{y} \times \boldsymbol{M} \boldsymbol{y}, \boldsymbol{g}_{\boldsymbol{f}}=\alpha \boldsymbol{y} \times \boldsymbol{f}(\boldsymbol{y}) \mathrm{e}$

$$
<\boldsymbol{g}, \boldsymbol{F}\rangle=\langle\alpha \boldsymbol{y} \times \boldsymbol{F}, \boldsymbol{F}\rangle=\langle\alpha \boldsymbol{y}, \boldsymbol{F} \times \boldsymbol{F}\rangle=0 .
$$

De um cálculo direto resulta que:

$$
<\operatorname{rot} \boldsymbol{g}_{\boldsymbol{M}}, \mathbf{1}>=-\left(\frac{m_{13}}{y_{1}^{2} y_{2}}+\frac{m_{23}}{y_{1} y_{2}^{2}}+\frac{m_{32}}{y_{1} y_{3}^{2}}+\frac{m_{12}}{y_{1}^{2} y_{3}}+\frac{m_{21}}{y_{2}^{2} y_{3}}+\frac{m_{31}}{y_{2} y_{3}^{2}}\right)
$$

e

$$
\begin{aligned}
<\operatorname{rot} \boldsymbol{g}_{\boldsymbol{f}}, \mathbf{1}>= & \alpha\left\{\left(\frac{f_{1}}{y_{2}}-\frac{f_{1}}{y_{1}}+\frac{\partial f_{1}}{\partial y_{1}}-\frac{\partial f_{1}}{\partial y_{2}}\right)+\right. \\
& \left.+\left(\frac{f_{3}}{y_{2}}-\frac{f_{3}}{y_{3}}+\frac{\partial f_{3}}{\partial y_{3}}-\frac{\partial f_{3}}{\partial y_{2}}\right)\right\}
\end{aligned}
$$

onde expressamos $(2.15)$ em termos de $f_{1}$ e $f_{3}$, ao invés de $f_{2}$ e $f_{3}$ devido a forma do sistema (2.11).

Obtemos agora uma generalização do critério de Bendixson-Dulac para uma superfície bidimensional $\mathcal{D}$ contida em $\mathbb{R}^{3}$. 
Teorema 3 Sejam $M=\left(m_{i j}\right)_{3 \times 3}$ uma matriz constante essencialmente näo negativa, $\boldsymbol{y}=\left(y_{1}, y_{2}, y_{3}\right)^{T}$ tal que $\langle\mathbf{1}, \boldsymbol{y}\rangle=1$ e $\boldsymbol{f}: \mathbb{R}_{+}^{3} \rightarrow \mathbb{R}_{+}^{3}$ de classe $\mathcal{C}^{1}$ satisfazendo $\langle\mathbf{1}, \boldsymbol{f}(\boldsymbol{y})\rangle=0$.

Seja $\boldsymbol{g}=\alpha \boldsymbol{y} \times \boldsymbol{F}(\boldsymbol{y})$, onde $\alpha=\left(y_{1} y_{2} y_{3}\right)^{-1}$. Se $<\operatorname{rot} \boldsymbol{g}_{f}, \mathbf{1}>\leq \mathrm{em}$ $\mathcal{D}^{0}=\mathcal{D}-\partial \mathcal{D}$, onde $\mathcal{D}=\left\{\left(y_{1}, y_{2}, y_{3}\right) \in \mathbb{R}^{3}+: y_{1}+y_{2}+y_{3}=1\right\}$, então não existem soluçòes periódicas de

$$
y^{\prime}=F(y)=M y-<\mathbf{1}, M y>y+f(y),
$$

em $\mathcal{D}^{0}$.

Além disso, se $\boldsymbol{F}_{i}(\boldsymbol{y})$ for nào negativo em $y_{i}=0$ para $i=1,2,3$ e positivo em pelo menos um $i$ entào este resultado vale no conjunto $\mathcal{D}$.

\section{Demonstração:}

Como $M$ é uma matriz constante e essencialmente não negativa, utilizando $(2.14)$ e $<\operatorname{rot} \boldsymbol{g}_{\boldsymbol{f}}, \mathbf{1}>\leq 0$, segue que $<\operatorname{rot} \boldsymbol{g}, \mathbf{1}><0$.

Suponha que exista uma solução periódica $\phi$ de período $\tau$ de $\boldsymbol{y}^{\prime}=\boldsymbol{F}(\boldsymbol{y})$ em $\mathcal{D}^{0}$.

Observando que $N=(\sqrt{3} / 3)(1,1,1)$ segue que:

$$
\begin{aligned}
0 & \neq \int_{S}<\operatorname{rot} g, N>d S \\
& =\int_{0}^{\tau}<g(\phi(t)), \phi^{\prime}(t)>d t \\
& =\int_{0}^{\tau}<g(\phi(t)), F(\phi(t))>d t=0 . \text { Contradição. }
\end{aligned}
$$

A condiçào $\boldsymbol{F}_{i}(\boldsymbol{y}) \geq 0$ para $i=1,2,3$, implica que o campo $\boldsymbol{F}$ nunca aponta em direção ao exterior de $\mathcal{D}$ quando avaliado em $\partial \mathcal{D}$ e como $\boldsymbol{F}_{i}(\boldsymbol{y})>0$ para ao menos um $i$, segue que $\partial \mathcal{D}$ não é um polígono de fase para o sistema. Assim, não existem soluções periódicas em $\mathcal{D}$.

Como aplicação imediata desse resultado temos:

Corolário 1 Suponha que $l_{s} \Phi \leq 0$ e $l_{r} \Psi \leq 0$, onde

$$
l_{s} \Phi=\frac{1}{s r}\left(\frac{\Phi}{s}+\Phi_{i}-\Phi_{s}\right) \text { e } l_{r} \Psi=\frac{1}{r s}\left(\frac{\Psi}{r}+\Psi_{i}-\Psi_{r}\right) .
$$

Então o modelo generalizado SIRS (2.8)-(2.10) não tem órbitas periódicas $\mathrm{em} \mathcal{D}$. 


\section{Prova:}

Como $b>0, \gamma \geq 0$ e $\rho \geq 0$ segue das hipóteses que:

$$
<\operatorname{rot} g, 1>=-\left(\frac{\gamma}{s r^{2}}+\frac{b}{s^{2} r}+\frac{b+\rho}{s^{2} i}\right)+l_{s} \Phi+l_{r} \Psi<0,
$$

assim o Teorema 3 implica a não existência de órbitas periódicas em $\mathcal{D}^{0}$.

Do fato do problema ser bem posto, is to é, o campo $\boldsymbol{F}$ nunca aponta para o exterior de $\mathcal{D}$ quando avaliado em $\partial \mathcal{D}$ e $s^{\prime}(0, i, r)=b+\rho r>0$ temos que $\partial \mathcal{D}$ não é um polígono de fase para o sistema, portanto não existem soluções periódicas em $\mathcal{D}$.

Corolário 2 Se $\Phi(s, i)=\operatorname{sh}(s+i)$ e $\Psi(r, i)=r j(r+i)$, onde $h$ e $j$ são funçóes arbitrárias diferenciáveis e não negativas, então o sistema dado por (Q.8)-(Q.10) não tem soluções periódicas no conjunto invariante $\mathcal{D}$.

\section{Prova:}

Basta verificar que $l_{s} \Phi=l_{r} \Psi=0$ e aplicar o Corolário 1.

Provaremos agora uma caracterização para as soluções da inequação de derivadas parciais $l_{s} \Phi<0$. Seja $\Phi(s, i)=s H(s, i)$, então

$$
\begin{aligned}
l_{s} \Phi & =\frac{1}{s r}\left(\frac{\Phi}{s}+\Phi_{i}-\Phi_{s}\right) \\
& =\frac{1}{s r}\left(H+s H_{i}-H-s H_{s}\right) \\
& =\frac{1}{r}\left(H_{i}-H_{s}\right),
\end{aligned}
$$

implicando que $l_{s} \Phi<0$ sempre que $H_{i}<H_{s}$. Esta desigualdade fornece a seguinte caracterização:

Teorema 4 Seja $\Delta=\left\{(s, i) \in \mathbb{R}_{+}^{2}: 0<s+i<1\right\}$, suponha que $H_{s}>H_{i}$, $G_{s}=G_{i}$ em $\bar{\Delta}$ e $H>G$ em $\partial \Delta$. Entĩo $H>G \mathrm{em} \bar{\Delta}$. Se as desigualdades forem invertidas, então temos que $H<G$ em $\bar{\Delta}$.

\section{Demonstração:}

Sejam $h(t)=H(t, c-t)$ e $g(t)=G(t, c-t)$, onde $t \in[0, c]$ e $c \in[0,1]$.

Entào segue que

$$
h^{\prime}(t)=\frac{\partial H}{\partial s}-\frac{\partial H}{\partial i}=H_{s}-H_{i}>0
$$




$$
g^{\prime}(t)=\frac{\partial G}{\partial s}-\frac{\partial G_{i}}{\partial i}=G_{s}-G_{i}=0 .
$$

Além disso, temos que

$$
\left.\begin{array}{rl}
h(0) & =H(0, c) \\
g(0) & =G(0, c)
\end{array}\right\} \Rightarrow h(0)>g(0)
$$

isto é,

$$
\left.\begin{array}{l}
(h-g)(0)>0 \\
(h-g)^{\prime}(t)>0
\end{array}\right\} \Rightarrow(h-g)(t)>0, \quad \forall t \in[0, c] .
$$

Portanto $H>G$ em $\bar{\Delta}$. No caso em que $H_{s}<H_{i}$ a demonstraçào é análoga.

\subsection{Um Modelo SIRI}

Nesta seção analisaremos o caso SI RI do modelo geral apresentado em (2.2), isto é, quando $\rho=\delta=0, \Phi(s, i)=\phi s$ e $\Psi(r, i)=\psi r$. Estudaremos em particular o comportamento próximo dos pontos de equilíbrio. Para a terminologia usada ver por exemplo [25].

Observemos que na Seção 2.3 mostramos que $l_{s} \Phi=l_{r} \Psi=0$ de modo que não existem soluções periódicas. Como $s+r+i=1$ o sistema (2.\$)(2.10) é essencialmente bidimensional e portanto podemos eliminar uma das variáveis. Eliminando a variável $r$, obtemos o seguinte sistema:

$$
\left\{\begin{array}{l}
s^{\prime}=b(1-s)-(\phi-\varepsilon) s i \\
i^{\prime}=i[(\phi-\psi) s+(\varepsilon-\psi) i-(\varepsilon+b+\gamma-\psi)]
\end{array}\right.
$$

Notemos que $\bar{\Delta}=\left\{(s, i) \in \mathbb{R}_{+}^{2}: 0 \leq s+i \leq 1\right\}$ é invariante: se $s=0$ então $s^{\prime}=b>0$, se $i=0$ então $i^{\prime}=0$ e sobre $s+i=1$ temos $(s+i)^{\prime}=-\gamma i \leq 0$, de modo que toda trajetória começando em $\bar{\Delta}$ permanece em $\bar{\Delta}$.

O sistema (2.17)-(2.18) tem um ponto de equilíbrio em $(1,0)$ correspondendo ao equilíbrio livre de doença DFE. Os autovalores da matriz Jacobiana no DFE são $-b$ e $\phi-(\varepsilon+b+\gamma)$ de modo que o DFE é um nó estável se o parâmetro $R_{0}=\frac{\phi}{(\varepsilon+b+\gamma)}<1$ e uma sela se $R_{0}>1$. 
Para determinar se existem equilíbrios endêmicos $\left(s_{*}, i_{*}\right) \operatorname{com} s_{*}>0$ e $i_{*}>0$ observemos que a isóclina $s^{\prime}=0$ é a hipérbole

$$
i=\frac{b(1-s)}{s(\phi-\varepsilon)}
$$

que passa pelo DFE e tem como assíntotas $s=0$ e $i=\frac{b}{(\varepsilon-\phi)}$. Essa hipérbole intercepta $\Delta$ se e somente se $\phi>b+\varepsilon$. As isóclinas $i^{\prime}=0$ são o eixo $s$ e a reta

$$
(\phi-\psi) s+(\varepsilon-\psi) i=(\varepsilon+b+\gamma-\psi)
$$

A análise depende de quatro quantidades: $\varepsilon+b+\gamma, \phi, \varepsilon, \psi$, sendo que as duas primeiras quantidades devem exceder a terceira, de modo que existem oito possiveis alternativas.

Se $\varepsilon+b+\gamma$ é a maior das quatro quantidades então existem 3 possíveis alternativas e em nenhuma delas existem pontos de equilíbrio em $\Delta$, além do globalmente assintoticamente estável DFE, pois a reta (2.19) ou não intercepta a hipérbole ou a intercepta fora de $\Delta$.

Se $\phi$ é a maior quantidade também existem 3 possíveis alternativas, o DFE é uma sela e existe no máximo um ponto de equilíbrio em $\Delta$. É fácil ver que se $\psi>\varepsilon$ (desse modo temos duas alternativas: $\phi>\varepsilon+b+\gamma>\psi>\varepsilon$ ou $\phi>\psi>\varepsilon+b+\gamma>\varepsilon)$ então (2.19) tem inclinação positiva e intercepta $\Delta$. O equilíbrio assim obtido é estável pois o traço da matriz Jacobiana é negativo e o determinante é positivo. A outra possivel alternativa é quando $\phi>\varepsilon+b+\gamma>\varepsilon>\psi$ de modo que a reta (2.19) tem inclinaçào negativa e pode interceptar a hipérbole em dois pontos. Para ver que um ponto está no interior de $\Delta$ e o outro está fora de $\Delta$ considere as intersecçòes das isóclinas com a reta $s+i=1$. Substituindo $1-s=i$ na hipérbole, obtemos $s=\frac{b}{\phi-\varepsilon}$, enquanto a intersecção de (2.19) com $s+i=1$ resulta em $s=\frac{b+\gamma}{\phi-\varepsilon}$.

Uma análise do campo revela que, quando $\phi$ é a maior quantidade, a direção do campo em torno do ponto de equilíbrio $\left(s_{*}, i_{*}\right)$ em $\Delta$ tem sentido anti-horário. Além disso, o eixo s é um separatriz que vai para o ponto de sela DFE e a separatriz partindo do DFE tem inclinação inicial $-\frac{(\phi-\varepsilon-\gamma)}{(\phi-\varepsilon)}$. Essa separatriz deve se aproximar do ponto de equilíbrio $\left(s_{*}, i_{*}\right)$ caso contrário 
existiria um órbita periódica. Assim, pelo Teorema de Poincaré-Bendixson, concluímos que, quando $\phi$ é a maior quantidade, o ponto de equilíbrio $\left(s_{*}, i_{*}\right)$ em $\Delta$ é um foco estável. (Ver Fig. 2.2).

Finalmente, quando $\psi$ é a maior quantidade (duas possíveis alternativas: $\psi>\phi>\varepsilon+b+\gamma>\varepsilon$ ou $\psi>\varepsilon+b+\gamma>\phi>\varepsilon$ ), a reta (2.19) intercepta a hipérbole em um ponto interior de $\Delta$ quando $R_{0}>1$ e em possivelmente dois pontos em $\Delta$ quando $R_{0}<1$. Em ambos os casos a direção do campo próximo à origem em $\mathbb{R}_{+}^{2}$ satisfaz $s^{\prime}>0$ e $i^{\prime}>0$. Se $\psi>\phi>\varepsilon+b+\gamma>\varepsilon$ então $R_{0}>1$ de modo que DFE é um ponto de sela. Analisando o campo numa vizinhança do ponto de equilíbrio $\left(s_{*}, i_{*}\right)$ em $\Delta$ concluímos que o mesmo deve ser um nó estável. (Ver Fig. 2.3).

Se $\psi>\varepsilon+b+\gamma>\phi>\varepsilon$ então $R_{0}<1$ de modo que DFE é um nó estável e quando a reta (2.19) intercepta a hipérbole em dois pontos em $\Delta$ o ponto com maior valor de $i$ deve ser um nó estável, enquanto que se o outro for um ponto de equilíbrio hiperbólico então o mesmo deve ser uma sela, pois se tomarmos uma vizinhança $V$ de DFE e considerarmos o conjunto $A=\bar{\Delta} \cap V^{c}$ veremos que o índice do campo em $\partial A$ é 0 e como um ponto de equilíbrio é estável (índice +1) o outro deve ser sela (índice -1 ). Se esse ponto de equilíbrio não for hiperbólico uma análise do campo numa vizinhança desse ponto indica que o mesmo deve ser uma sela. (Ver Fig. 2.4).

A separatriz que vai para esse ponto de sela divide $\Delta$ em duas bases de atração. Uma dessas separatrizes está muito próxima do eixo $s$, isto indica que se o número inicial de infectivos é muito baixo a doença se extingue, pois a trajetória tende a permanecer na base de atração do DFE. Um pequeno aumento no número de infectivos pode iniciar uma situação endêmica, pois a trajetória pode tender a base de atração de $\left(s_{*}, i_{*}\right)$. Assim, essa separatriz serve como um curva limiar determinando em qual base de atração a trajetória permanecerá. (Ver Fig. 2.4). 


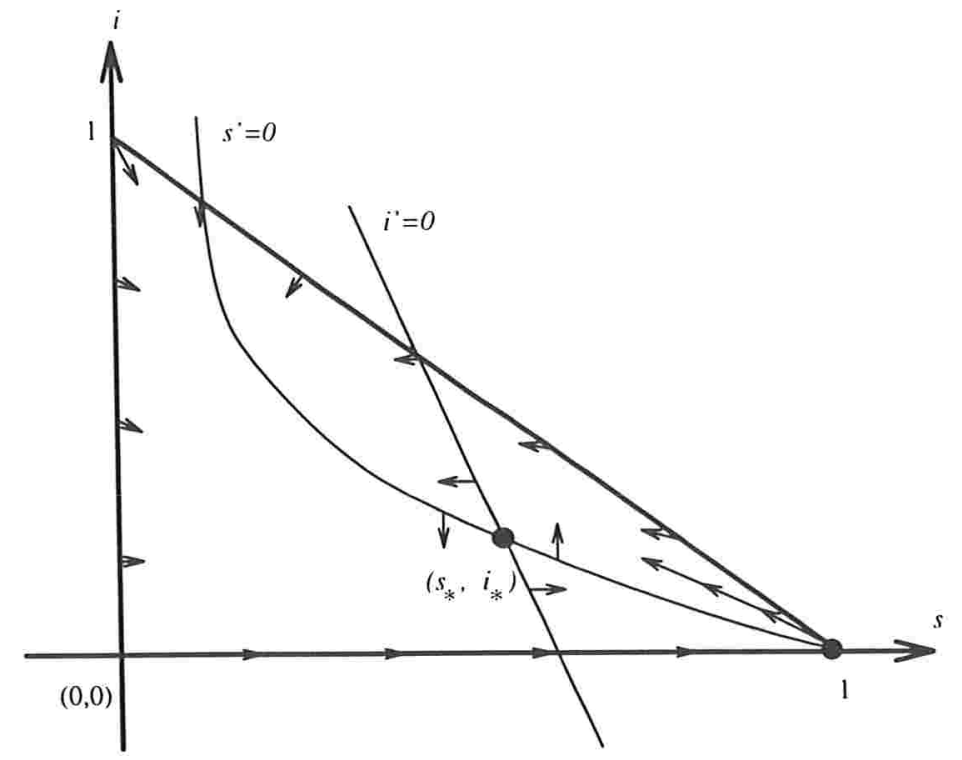

Fig. 2.2 Plano de fase mostrando isóclinas e separatrizes quando $\phi>\varepsilon+b+\gamma>\varepsilon>\psi\left(R_{0}>1\right)$.

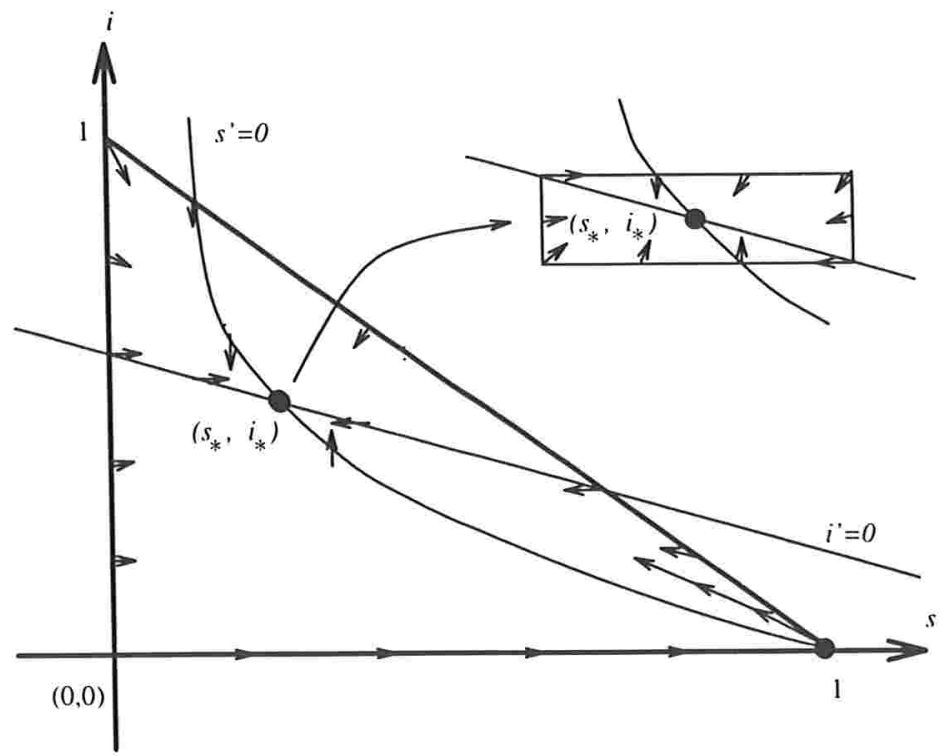

Fig. 2.3 Plano de fase mostrando isóclinas e separatrizes quando $\psi>\phi>\varepsilon+b+\gamma>\varepsilon\left(R_{0}>1\right)$. 


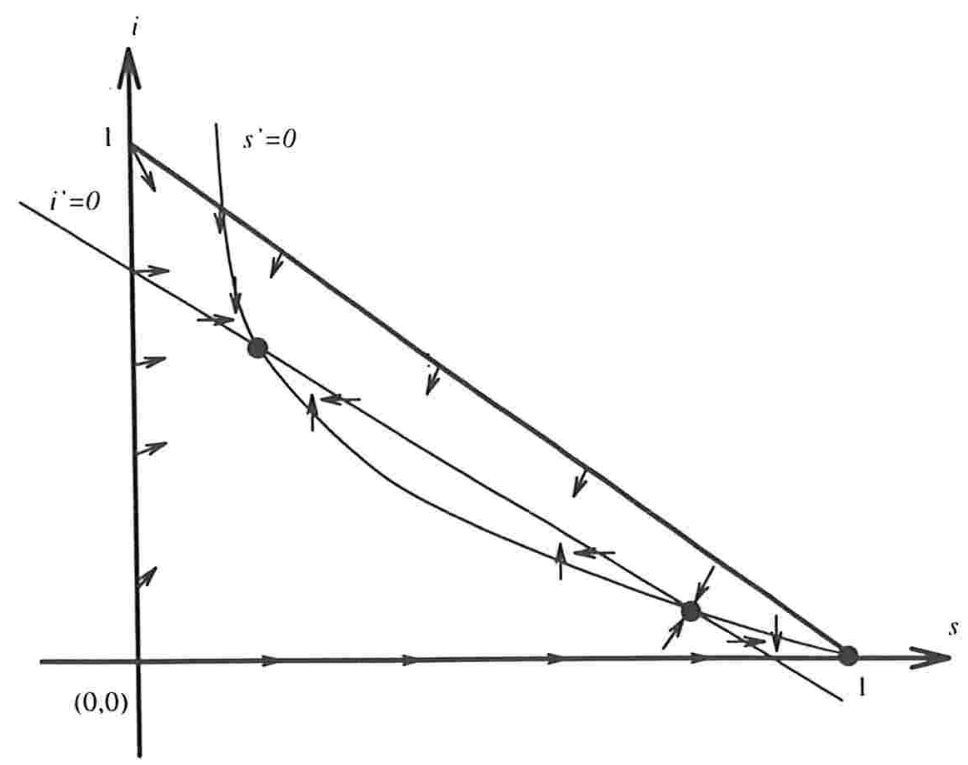

Fig. 2.4 Plano de fase mostrando isóclinas e separatrizes quando $\psi>\varepsilon+b+\gamma>\phi>\varepsilon\left(R_{0}<1\right)$.

\subsection{Soluções Periódicas}

Antes de eśtudar uma situação que conduza a uma solução periódica, é conveniente analisar o caso geral eliminando a variável $s$ das equaçòes (2.9) e (2.10). Lembrando que $s=1-i-r$ temos:

$$
\left\{\begin{array}{l}
i^{\prime}=i[-(b+\varepsilon+\gamma)+\varepsilon i+\delta r+\Phi(1-i-r, i)+\Psi(r, i)], \\
r^{\prime}=i[\gamma-\Psi(r, i)]+r[-(b+\delta+\rho)+\varepsilon i+\delta r] .
\end{array}\right.
$$

Um ponto de equilíbrio é imediato: o equilíbrio livre de doença DFE na origem. Qualquer outro depende do valor das funções $\Phi(1-i-r, i)$ e $\Psi(r, i)$ no conjunto

$$
\bar{\Delta}_{1}=\left\{(i, r) \in \mathbb{R}_{+}^{2}: 0 \leq i+r \leq 1\right\} .
$$

Denotaremos qualquer outro ponto de equilíbrio (se existir) pela notação $\left(i_{*}, r_{*}\right)$.

Os autovalores da matriz Jacobiana no DFE são:

$$
-(\rho+b+\delta) \text { e }\left(\varepsilon+b+\gamma_{i}\right)\left(R_{0}-1\right)
$$


onde $R_{0}=(\Phi(1,0)+\Psi(0,0)) /(\varepsilon+b+\gamma)$. Assim, o DFE é um nó estável se $R_{0}<1$ e se $R_{0}>1$ o DFE é um ponto de sela.

Em qualquer outro ponto de equilíbrio $\left(i_{*}, r_{*}\right)$ a matriz Jacobiana é dada por:

$$
J=\left[\begin{array}{cc}
i\left(\varepsilon+[\Phi(1-i-r, i)+\Psi(r, i)]_{i}\right) & i\left(\delta+[\Phi(1-i-r, i)+\Psi(r, i)]_{r}\right) \\
\gamma+\varepsilon r-\Psi(r, i)-i \Psi_{i}(r, i) & \delta r+i\left[(\Psi(r, i)-\gamma) / r-\Psi_{r}(r, i)\right]
\end{array}\right] .
$$

Assumiremos agora que

$$
\Phi(s, i)=\phi \text { si e } \Psi(r, i)=0 .
$$

Nesse caso o sistema (2.20) se reduz a

$$
\left\{\begin{array}{l}
i^{\prime}=i[-(b+\varepsilon+\gamma)+\varepsilon i+\delta r+i \phi(1-i-r)], \\
r^{\prime}=\gamma i+r[-(b+\delta+\rho)+\varepsilon i+\delta r] .
\end{array}\right.
$$

Assim, $l_{s} \Phi=\phi / r$ e $l_{r} \Psi=0$, donde temos que:

$$
\begin{aligned}
<\operatorname{rot} \boldsymbol{g}, \mathbf{1}> & =-\left(\frac{\gamma}{s r^{2}}+\frac{b}{s^{2} r}+\frac{b+\rho}{s^{2} i}\right)+l_{s} \Phi+l_{r} \Psi \\
& =\frac{1}{\operatorname{sir}}\left(\phi s i-\frac{\gamma i}{r}-\frac{b i}{s}-\frac{(b+\rho) r}{s}\right) .
\end{aligned}
$$

Observemos que se $b>\phi$ ou $\gamma>\phi$ então (2.23) é negativa e nenhuma solução periódica é possível. Entretanto, para pequenos valores de $b$ e $\gamma$ tais que $b<\phi$ e $\gamma<\phi$, o termo entre parênteses pode ser positivo ou negativo dependendo dos valores de $s, i, r$ e $\rho$. Assim, soluções periódicas são possíveis. Para este caso a matriz Jacobiana se torna:

$$
J=\left[\begin{array}{cc}
i(\varepsilon+\phi(1-2 i-r)) & i(\delta-\phi i) \\
\gamma+\varepsilon r & \delta r-i \gamma / r
\end{array}\right] .
$$

Os pontos de equilíbrio interiores $\left(i_{*}, r_{*}\right)$ estão localizados na intersecção das hipérboles

$$
\begin{aligned}
\phi i^{2}+\phi i r-(\phi+\varepsilon) i-\delta r+(b+\varepsilon+\gamma) & =0, \\
\varepsilon i r+\delta r^{2}+\gamma i-(b+\delta+\rho) r & =0 .
\end{aligned}
$$


Usando estas expressões, podemos escrever o traço e determinante de (2.24) da seguinte maneira:

$$
\begin{aligned}
\operatorname{tr} J & =(\varepsilon i+\delta r)-i[\gamma / r+\phi(2 i+r-1)], \\
& =(b+\varepsilon+\gamma)-i[\gamma / r+\phi i], \\
\frac{\operatorname{det} J}{i} & =\phi(2 i+2 r-1)(\gamma i / r-\delta r)+(\varepsilon i+\delta r)(\phi r-\gamma / r),
\end{aligned}
$$

onde $(i, r)=\left(i_{*}, r_{*}\right)$. No que segue, adotaremos as seguintes desigualdades:

$$
\begin{aligned}
& 0<\phi<\min \{4 \varepsilon, 16(\varepsilon-\delta) .16 \delta\} \\
& 0<2 \varepsilon<\delta+\sqrt{\delta \phi} .
\end{aligned}
$$

A condiçào que $\delta<\varepsilon$ implica que a proporção de mortes relacionadas à doença é maior na classe $I$ do que na classe $R$, o que é uma hipótese razoável.

Começamos considerando o caso $b=\gamma=0$ e estenderemos, por continuidade, os resultados assim obtidos para pequenos valores de $b$ e $\gamma$. Assim, o sistema (2.22) se reduz a

$$
\left\{\begin{array}{l}
i^{\prime}=i[-\varepsilon+\varepsilon i+\delta r+i \phi(1-i-r)] \\
r^{\prime}=r[-(\delta+\rho)+\varepsilon i+\delta r]
\end{array}\right.
$$

Observemos que o conjunto $\bar{\Delta}_{1}$ é invariante em relação ao sistema (2.32): se $i=0$ em (2.32) temos que $i^{\prime}=0$, se $r=0$ então $r^{\prime}=0$ e se $i+r=1$ temos que $(i+r)^{\prime}=-\rho r \leq 0$, pois $s=0$. Portanto qualquer órbita começando em $\bar{\Delta}_{1}$ deve permanecer em $\bar{\Delta}_{1}$.

As isóclinas $i^{\prime}=0$ são o eixo $r$ e a hipérbole

$$
r=(1-i)(\phi i-\varepsilon) /(\phi i-\delta),
$$

enquanto as isóclinas $r^{\prime}=0$ se degeneram em duas retas: o eixo $i$ e

$$
r=(\delta+\rho-\varepsilon i) / \delta .
$$

Resolvendo a hipérbole e essa última reta simultaneamente para $i$, obtemos a seguinte equação quadrática:

$$
(\varepsilon-\delta) \phi i^{2}-\rho \phi i+\delta(\rho-(\varepsilon-\delta))=0
$$

Se $\rho=k(\varepsilon-\delta)$ então (2.33) se torna

$$
i^{2}-k i-(1-k) \delta / 0=0 .
$$


que tem por raiz

$$
i=(k / 2)\left[1+\sqrt{1+4 \delta(1-k) /\left(\phi k^{2}\right)}\right],
$$

logo existe pelo menos um ponto de equilíbrio em $\mathbb{R}_{+}^{2}$ quando $0<k<1$.

Para ver que o ponto de equilíbrio $\left(i_{*}, r_{*}\right)$ está em $\bar{\Delta}_{1}$, observemos que:

$$
\begin{aligned}
& r=(1-k)+(k \varepsilon / 2 \delta)\left[1-\sqrt{1+4 \delta(1-k) /\left(\phi k^{2}\right)}\right], \\
& s=1-i-r=(i-k)(\varepsilon-\delta) / \delta .
\end{aligned}
$$

Notemos que $r$ e $s$ são estritamente positivos, pois

$$
\begin{aligned}
r>0 & \Leftrightarrow(1-k)+(k \varepsilon / 2 \delta)\left[1-\sqrt{1+4 \delta(1-k) /\left(\phi k^{2}\right)}\right]>0 \\
& \Leftrightarrow 2 \delta(1-k) /(k \varepsilon)+1>\sqrt{1+4 \delta(1-k) /\left(\phi k^{2}\right)} \\
& \Leftrightarrow \delta(1-k) /\left(k \varepsilon^{2}\right)+1 / \varepsilon>1 /(\phi k) \\
& \Leftrightarrow(1 / k)\left[\left(\delta \phi / \varepsilon^{2}\right)-1\right]+(\phi / \varepsilon)(1-\delta / \varepsilon)>0
\end{aligned}
$$

e essa última desigualdade é verdadeira visto que $\delta \phi>\varepsilon^{2}$ por $(2.31)$ e $\varepsilon>\delta$ por (2.30). É claro que $s>0$ pois $i>k$ por (2.35). Portanto existem quatro pontos de equilíbrio em $\bar{\Delta}_{1}$ : o DFE em $(0,0),(\varepsilon / \phi, 0),(1,0)$ e $\left(i_{*}, r_{*}\right)$. (Ver Fig. 2.5).

É fácil ver que DFE é sempre um nó estável já que $R_{0}=0$.

No ponto de equilíbrio $(\varepsilon / \phi, 0)$ temos uma sela, pois:

$$
J(\varepsilon / \phi, 0)=\left[\begin{array}{cc}
\varepsilon(\phi-\varepsilon) / \phi & (\varepsilon / \phi)(\delta-\varepsilon) \\
0 & \varepsilon^{2}-\phi(\rho+\delta)
\end{array}\right],
$$

cujo autovalores são $\varepsilon(\phi-\varepsilon) / \phi$ e $\varepsilon^{2}-\phi(\rho+\delta)$, sendo que o primeiro é positivo visto que $\phi>\varepsilon$ e o segundo é negativo por (2.31).

No ponto de equilíbrio $(1,0)$ temos uma sela quando $0<k<1$, pois:

$$
J(1,0)=\left[\begin{array}{cc}
\varepsilon-\phi & \delta-\phi \\
0 & k(\varepsilon-\delta)
\end{array}\right],
$$

cujo autovalores são $\varepsilon-\phi$ e $k(\varepsilon-\delta)$ e o primeiro é negativo já que $\phi>\varepsilon$ e 
$k(\varepsilon-\delta)>0$ se $0<k<1$.

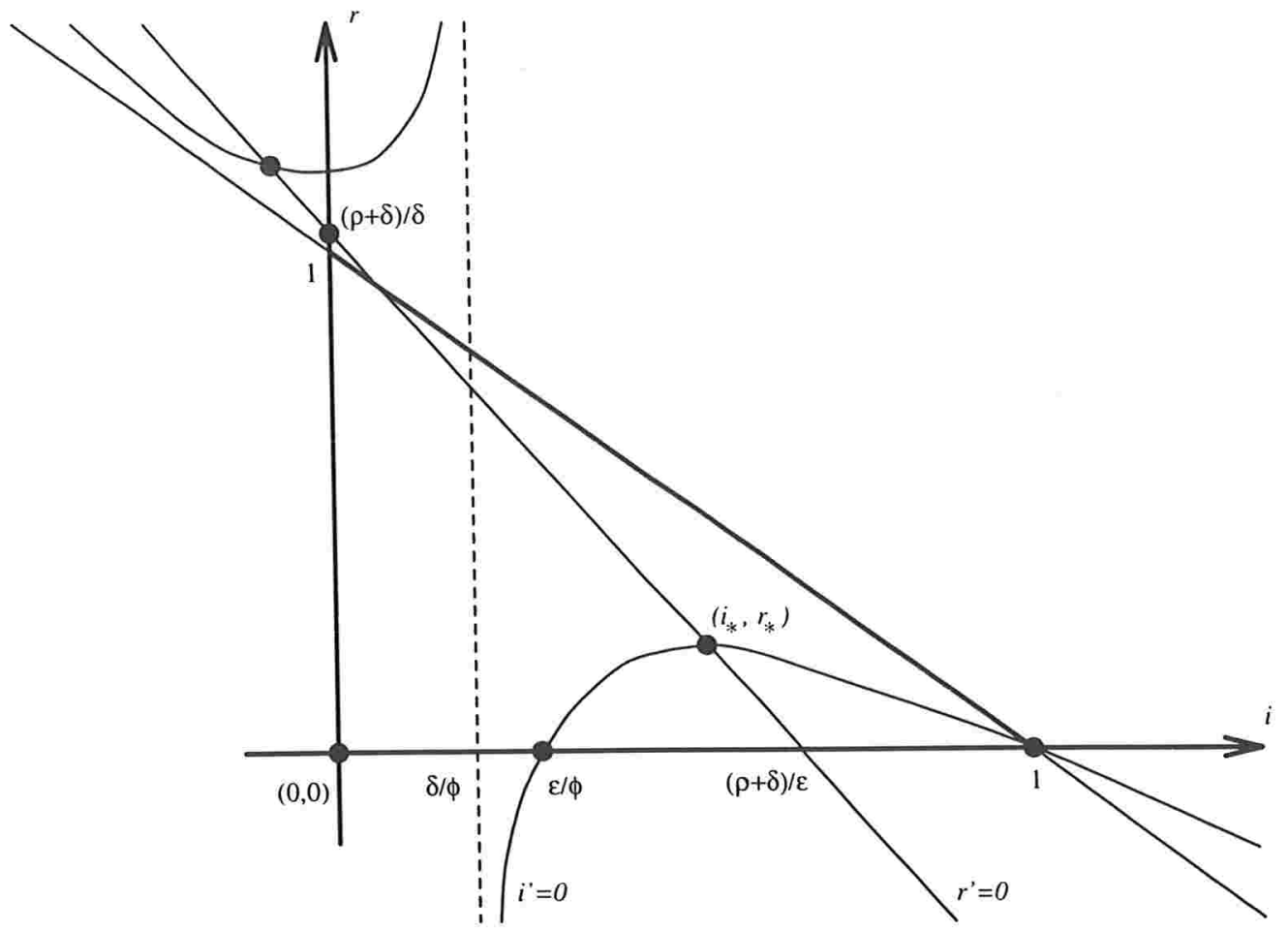

Fig. 2.5 Plano de fase mostrando as isóclinas quando $b=\gamma=0$, $\Phi(s, i)=\phi$ si e $\Psi(r, i)=0$.

Consideraremos a natureza de $\left(i_{*}, r_{*}\right)$ em $k=0$ e $k=1 / 2$.

Se $k=0$ então $i^{2}=\delta / \phi$, de modo que $i=\delta / \sqrt{\delta \phi}, r=1-\varepsilon i / \delta=$ $1-\varepsilon / \sqrt{\delta \phi}$ e $s=(\varepsilon-\delta) / \sqrt{\delta \phi}>0$, implicando que $s<1$ por (2.31).

Por (2.29) temos que det $J=\phi i r[\varepsilon i-\delta r-2 \delta i+\delta]=2 \operatorname{ir}(\varepsilon-\delta) \sqrt{\phi \delta}>0$ e por $(2.28) \operatorname{tr} J=(\varepsilon-\delta)>0$.

O discriminante do polinômio característico da matriz Jacobiana é igual a $(\operatorname{tr} J)^{2}-4 \operatorname{det} J=(\varepsilon-\delta)[(\varepsilon-\delta)-\delta \delta(1-\varepsilon / \sqrt{\delta \phi})]<0$, já que

$$
(1 / \delta)[(\varepsilon-\delta)-8 \delta(1-\varepsilon / \sqrt{\delta \phi})]=\frac{\varepsilon}{\delta}+\frac{8 \varepsilon}{\sqrt{\delta \phi}}-9
$$

e por $(2.31)$

$$
\frac{\varepsilon}{\delta}+\frac{8 \varepsilon}{\sqrt{\delta \phi}}-9<\frac{1}{2}(8 \sqrt{\delta / \phi}-1)(1-\sqrt{\phi / \delta}) .
$$


De fato:

$$
\begin{aligned}
\frac{\varepsilon}{\delta}+\frac{8 \varepsilon}{\sqrt{\delta \phi}}-9 & <\frac{1}{2 \delta}(\delta+\sqrt{\delta \phi})+\frac{4}{\sqrt{\delta \phi}}(\delta+\sqrt{\delta \phi})-9 \quad(\text { por }(2.31)) \\
& =\frac{1}{2}\left(\frac{\sqrt{\phi}}{\sqrt{\delta}}-9+8 \frac{\sqrt{\delta}}{\sqrt{\phi}}\right) \\
& =\frac{1}{2}(8 \sqrt{\delta / \phi}-1)(1-\sqrt{\phi / \delta})
\end{aligned}
$$

o primeiro termo entre parênteses é positivo pois $\phi<16 \delta$ por (2.30), enquanto que o último é negativo. Portanto $\left(i_{*}, r_{*}\right)$ é um foco instável.

Se $k=1 / 2$ então temos que $i=[1+\sqrt{1+8 \delta / \phi}] / 4$ e portanto $r=(1 / 2)+$ $(\varepsilon / \delta)[1-\sqrt{1+\delta \delta / \phi}] / 4$ e tr $J=(2 \varepsilon-\delta-\phi i) / 2<0$, por $(2.31)$ e pelo fato de que $i>\sqrt{\delta / \phi}$ por $(2.35)$. Além disso, det $J=\operatorname{\phi ir}(\varepsilon-\delta)(\sqrt{1+\delta \delta / \phi}) / 2>0$ e o discriminante é igual a

$$
\left(\frac{\phi i}{2}-\left(\varepsilon-\frac{\delta}{2}\right)\right)^{2}-2(\varepsilon-\delta)(\sqrt{1+\delta \delta / \phi})\left(\frac{\phi i}{2}-\frac{\varepsilon}{2}\right),
$$

que é negativo, já que

$$
0<\left(\frac{\phi i}{2}-\left(\varepsilon-\frac{\delta}{2}\right)\right)<\left(\frac{\phi i}{2}-\frac{\varepsilon}{2}\right)
$$

por (2.30) e também que

$$
\left(\frac{\phi i}{2}-\left(\varepsilon-\frac{\delta}{2}\right)\right)<2(\varepsilon-\delta)(\sqrt{1+8 \delta / \phi}) .
$$

De fato: sabemos por (2.30) que $\phi<4 \varepsilon, \operatorname{logo}$ se $a=\sqrt{1+8 \delta / \phi}$ então

$$
\begin{aligned}
\phi / 8<\varepsilon-\delta / 2 & \Rightarrow 2(\varepsilon-\delta) a+\phi / \delta-(\varepsilon-\delta / 2)<2(\varepsilon-\delta) a \\
& \Rightarrow(\phi / 8) a+\phi / \delta-(\varepsilon-\delta / 2)<2(\varepsilon-\delta) a \quad(\text { por }(2.30)) \\
& \Rightarrow\left(\frac{\phi i}{2}-\left(\varepsilon-\frac{\delta}{2}\right)\right)<2(\varepsilon-\delta)(\sqrt{1+\delta \delta / \phi}) .
\end{aligned}
$$

Portanto $\left(i_{*}, r_{*}\right)$ é um foco estável. Logo existe $k_{0}, 0<k_{0}<1 / 2$, tal que $\operatorname{tr} J\left(k_{0}\right)=0$. Vamos mostrar que neste ponto temos uma bifurcação de Hopf. Não é difícil encontrar os valores de $k_{0}, i_{*}\left(k_{0}\right)$ e $r_{*}\left(k_{0}\right)$ para os quais 
a bifurcação de Hopf ocorre, basta substituirmos (2.35) em tr $J=0$ usando (2.28). Resolvendo a equação quadrática obtemos

$$
k_{0}=\frac{\varepsilon-\delta}{\sqrt{\varepsilon \phi}-\delta},
$$

donde, por (2.35) e (2.36) temos que:

$$
i_{*}\left(k_{0}\right)=\sqrt{\varepsilon / \phi} \text { e } r_{*}\left(k_{0}\right)=\frac{(1-\sqrt{\varepsilon / \phi})(\sqrt{\phi \varepsilon}-\varepsilon)}{\sqrt{\phi \varepsilon}-\delta} .
$$

Os autovalores da matriz Jacobiana em $\left(i_{*}, r_{*}\right)$ sào da forma:

$$
\lambda=\frac{\operatorname{tr} J \pm \sqrt{(\operatorname{tr} J)^{2}-4 \operatorname{det} J}}{2}
$$

portanto, por (2.28)

$$
\begin{aligned}
\operatorname{Re} \lambda & =\frac{\operatorname{tr} J}{2} \\
& =\frac{\varepsilon-i_{*}^{2} \phi}{2} .
\end{aligned}
$$

Logo $\operatorname{Re} \lambda\left(k_{0}\right)=\operatorname{tr} J\left(k_{0}\right)=0$ e derivando implicitamente em (2.34) temos que:

$$
\begin{aligned}
\left.\frac{d}{d k} \operatorname{Re} \lambda(k)\right|_{k=k_{0}} & =-i_{*}\left(k_{0}\right) \phi \frac{\partial i}{\partial k} \\
& =\frac{-i_{*}\left(k_{0}\right) \phi\left(i_{*}\left(k_{0}\right)-\delta / \phi\right)}{\left(2 i_{*}\left(k_{0}\right)-k_{0}\right)} .
\end{aligned}
$$

Observemos que $2 i_{*}\left(k_{0}\right)>k_{0}$ por $(2.35)$.

Portanto

$$
\left.\frac{d}{d k} \operatorname{Re} \lambda(k)\right|_{k=k_{0}}<0
$$

pois $i_{*}\left(k_{0}\right)>\delta / \phi$ por $(2.30)$ e $(2.31)$.

Usando (2.29), (2.35), (2.37) e (2.40) obtemos os autovalores $\pm i \omega_{0}$ quando $k=k_{0}$ e um cálculo longo mas rotineiro conduz a

$$
\omega_{0}^{2}=(\varepsilon-\delta)\left(\varepsilon+\delta-\frac{2 \varepsilon \delta}{\sqrt{\varepsilon \phi}}\right)\left(\frac{\sqrt{\varepsilon O}-\varepsilon}{\sqrt{\varepsilon 0}-\delta}\right)^{2},
$$


de modo que $\omega_{0}>0$. Portanto, pelo Teorema de Bifurcaçào de Hopf (ver Apêndice), existe uma órbita periódica cujo período é próximo de $2 \pi / \omega_{0}$ para cada $k \approx k_{0}$.

Assumiremos agora que $b>0$ e que $\gamma=0$. Assim, o sistema (2.22) se reduz a.

$$
\left\{\begin{array}{l}
i^{\prime}=i[-(b+\varepsilon)+\varepsilon i+\delta r+i \phi(1-i-r)] \\
r^{\prime}=r[-(b+\delta+\rho)+\varepsilon i+\delta r] .
\end{array}\right.
$$

A isóclina $i^{\prime}=0$ novamente consiste do eixo $r$ e da hipérbole

$$
r=[(1-i)(\phi i-\varepsilon)-b] /(\phi i-\delta)
$$

que permanece abaixo da hipérbole anterior em $\overline{\Delta_{1}}$ quando $i>\delta / \phi$. Para $(o-\varepsilon)^{2} / 4 \phi>b$, a nova hipérbole interceptará o eixo $i$ em dois pontos $i_{1}$ e $i_{2}$ entre $\varepsilon / \phi$ e 1 .

A isóclina $r^{\prime}=0$ consiste do eixo $i$ e da reta

$$
\varepsilon i+\delta r=b+\delta+\rho .
$$

Para $i_{1}<(b+\delta+\rho) / \varepsilon<i_{2}$, a reta intercepta a hipérbole no ponto $\left(i_{*}, r_{*}\right)$ com $i_{*}$ entre as raízes da hipérbole.

Encontramos quatro pontos de equilíbrio em $\overline{\Delta_{1}}$ : o DFE na origem, $\left(i_{1}, 0\right)$, $\left(i_{2}, 0\right)$ e $\left(i_{*}, r_{*}\right)$. (Ver Fig. 2.6.) 


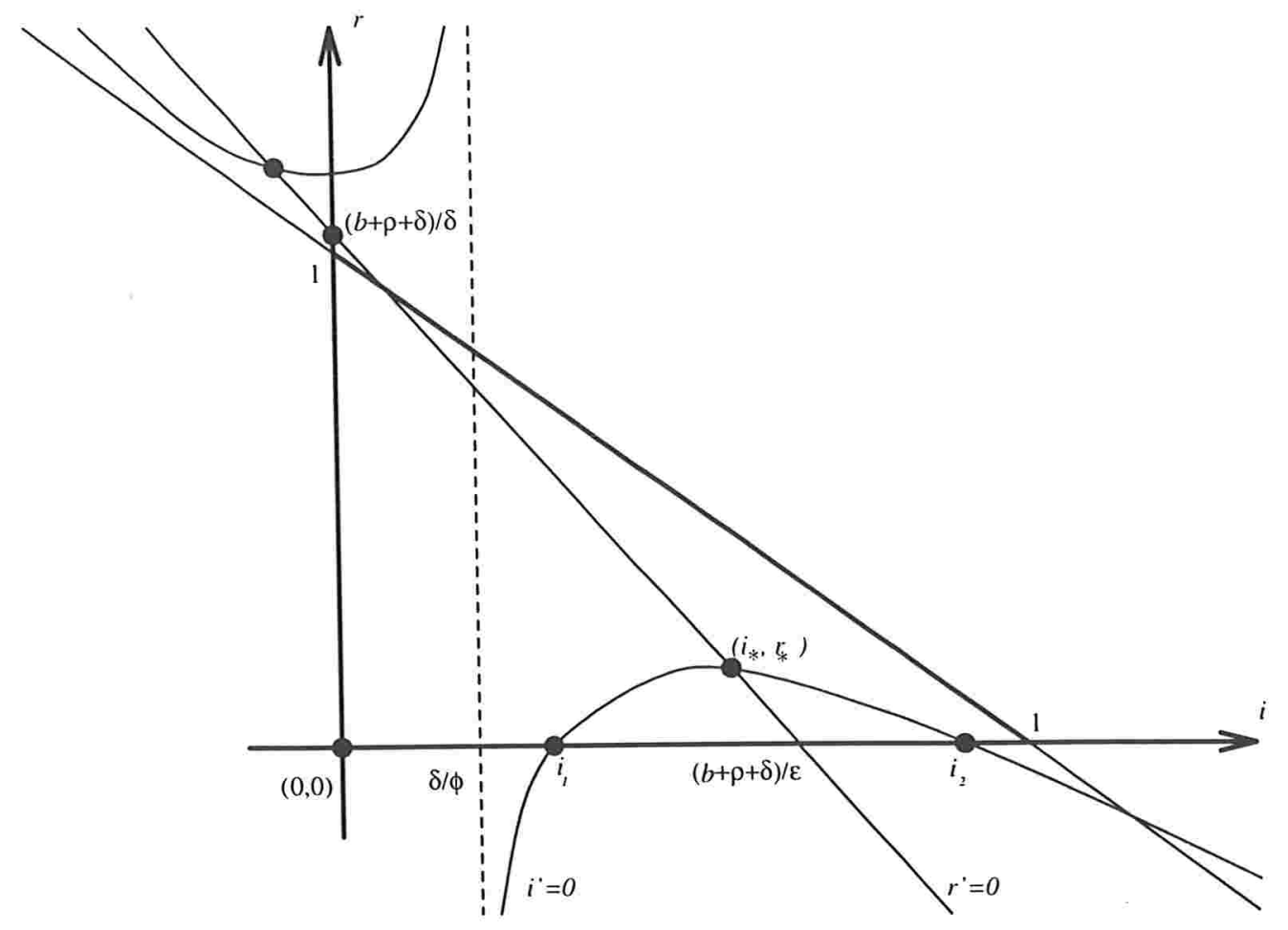

Fig. 2.6 Plano de fase mostrando as isóclinas quando $b>0, \gamma=0$, $\Phi(s, i)=\phi$ si e $\Psi(r, i)=0$.

O DFE é novamente um nó estável com autovalores $-(b+\varepsilon),-(b+\delta+\rho)$ e como

$$
J\left(i_{j}, 0\right)=\left[\begin{array}{cc}
2 \phi i_{j}\left(\frac{1+\varepsilon / \phi}{2}-i_{j}\right) & i_{j}\left(\delta-\phi i_{j}\right) \\
0 & \varepsilon\left(i_{j}-\frac{b+\delta+\rho}{\varepsilon}\right)
\end{array}\right], j=1,2,
$$

segue que $\left(i_{1}, 0\right)$ e $\left(i_{2}, 0\right)$ são pontos de sela, pois $i_{1}<(1+\varepsilon / \phi) / 2<i_{2}$ e $i_{1}<(b+\delta+\rho) / \varepsilon<i_{2}$.

A análise em $\left(i_{*}, r_{*}\right)$ é muito similar aquela feita acima e por continuidade concluímos que se $b$ for suficientemente pequeno e $k=0$ teremos um foco instável, enquanto que se $k=1 / 2$ teremos um foco estável e uma bifurcação de Hopf ocorre entre esses dois valores. 
Continuando com esse processo para $b$ e $\uparrow$ suficientemente pequenos. temos que as isóclinas $i^{\prime}=0$ novamente consistirào do eixo $i$ e da hipérbole

$$
r=[(1-i)(\phi i-\varepsilon)-b-i] /(\phi i-\delta)
$$

que permanece abaixo da hipérbole anterior em $\overline{\lambda_{1}}$ para $i>\delta / \phi$, mas a isóclina $r^{\prime}=0$ se torna a hipérbole (2.26).

Para $\gamma$ suficientemente pequeno, essa hipérbole pode ser aproximada pelas duas retas isóclinas do caso $b>0$ e $\gamma=0$. Desta rez, teremos somente três pontos de equilíbrio em $\overline{\Delta_{1}}$ : o DFE, o ponto $\left(i_{*}, r_{*}\right)$ e o ponto $P$ próximo à $\left(i_{1}, 0\right)$. O equilíbrio correspondente a $\left(i_{2}, 0\right)$ agora permanece no quarto quadrante, logo não tem significado biológico. O traço em $P$ é dado por (2.27) ou (2.28) e por continuidade concluímos que $P$ é um ponto de sela. $O$ ponto $\left(i_{*}, r_{*}\right)$ é um foco instável se $k$ estiver próximo de 0 e é um foco estável se $k$ estiver próximo de $1 / 2$ e teremos novamente uma bifurcação de Hopf entre esses dois valores.

Para investigar a estabilidade das soluções periódicas associadas com as bifurcações de Hopf acima, diferentemente do artigo original da qual esse capítulo se baseia onde tal estabilidade foi estudada por meio de métodos numéricos, faremos esta análise por meios analíticos e invocaremos o critério para bifurcações de Hopf super ou sub-críticas como feito em Liu et al. (1986) [16] (ver Apêndice).

Estudaremos a estabilidade da soluçào periódica no caso em que $b=\gamma=0$ e que $\Phi(s, i)=\phi$ si e $\Psi(r, i)=0$. Assim, por (2.32) temos que:

$$
\left\{\begin{array}{l}
i^{\prime}=-\varepsilon i+(\varepsilon+\phi) i^{2}+\delta i r-\phi i^{2} r-\phi i^{3} \\
r^{\prime}=-(\rho+\delta) r+\varepsilon i r+\delta r^{2}
\end{array} .\right.
$$

A matriz Jacobiana em $\left(i_{*}\left(k_{0}\right), r_{*}\left(k_{0}\right), k_{0}\right)$ é igual a

$$
J_{*}=\left(\begin{array}{cc}
-\delta r_{*} & \delta \sqrt{\varepsilon / \phi}-\varepsilon \\
\varepsilon r_{*} & \delta r_{*}
\end{array}\right),
$$

donde, usando a notação do Teorema 12 do Apêndice, temos que

$D=-\delta r_{*}, C=\varepsilon r_{*}, B=\varepsilon-\delta \sqrt{\varepsilon / \phi}$ e $\omega^{2}=B C-D^{2}=(\varepsilon-\delta \sqrt{\varepsilon / \phi}) \varepsilon r_{*}-\delta^{2} r_{*}^{2}$. 
As derivadas calculadas em $\left(i_{*}\left(k_{0}\right), r_{*}\left(k_{0}\right), k_{0}\right)$ estào listadas abaixo:

$$
\begin{array}{ll}
F_{i i}=2(\varepsilon+\phi)-2 \phi r_{\times}-6 \phi i_{*}, & F_{i r r}=0, \\
F_{i r}=\delta-2 \phi i_{\times}, & G_{r r r}=0, \\
F_{i i r}=-2 \phi, & G_{i i r}=0, \\
F_{i i i}=-6 \phi, & G_{i r r}=0, \\
G_{r r}=2 \delta, & F_{r r}=0, \\
G_{i r}=\varepsilon, & G_{i i}=0 .
\end{array}
$$

Substituindo-se esses valores na equação (A.4) e simplificando-a com auxílio do programa matemático $\mathrm{MAPLE}^{1} \mathrm{~V}$ (Release 1.1) temos que:

$$
A K=3 \delta \varepsilon+\delta^{2}-(3 \delta+\varepsilon) \sqrt{\phi \varepsilon},
$$

onde

$$
K=\frac{\omega^{2} \varepsilon r_{*}(\delta-\sqrt{\phi \varepsilon})^{2}}{2(\varepsilon-\delta)(\sqrt{\phi}-\sqrt{\varepsilon})^{2} \sqrt{\phi} \sqrt{\varepsilon^{3}}}
$$

e é claro que $K$ é positivo. Logo, o sinal de $A$ é negativo, pois:

$$
(3 \delta+\varepsilon) \sqrt{\phi \varepsilon}>\varepsilon(3 \delta+\varepsilon)=3 \delta \varepsilon+\varepsilon^{2}>3 \delta \varepsilon+\delta^{2} .
$$

Portanto, pelo Teorema 12 do Apêndice, a solução periódica é estável. Para $b, \gamma>0$ pequenos o resultado segue por continuidade.

\footnotetext{
${ }^{1}$ MAPLE é uma marca registrada da Waterloo Maple Software.
} 


\section{Capítulo 3}

\section{Um Modelo de Transmissão de HIV e AIDS}

\subsection{Preliminares}

A sindrome da imunodeficiência adquirida AIDS (acquired immunodeficiency syndrome) foi identificada como uma nova doença em 1981 nos Estados Unidos. Em 1983 o vírus da imunodeficiência humana HIV (human immunodeficiency virus) foi identificado como o agente causador da AIDS.

Essa epidemia é de grande interesse da saúde pública pois o HIV é infeccioso, causa severa morbidade e morte na maioria, se não em todos aqueles infectados, e freqüentemente ocorre em pessoas relativamente jovens.

Há vários aspectos incomuns do HIV e da AIDS que tornam essa nova doença diferente das demais. Por exemplo, o tempo médio da infecção com HIV até a AIDS é aproximadamente 10 anos, que é muito maior do que os períodos de menos de 10 dias para sarampo, caxumba e catapora. Além disso, como os indivíduos infectados não se recuperam, eles continuam a infectar outras pessoas durante toda sua vida.

Este capítulo é baseado num trabalho realizado por Herbert W. Hethcote e James W. van Ark (1992) [12]. 


\subsection{Informações Gerais sobre o HIV e AIDS}

Os três conhecidos modos de transmissão do HIV são: contato sexual, contato direto com fluidos ou sangue infectados com HIV e transmissão perinatal de uma mãe infectada para sua criança. Não há evidências de propagação através de assentos sanitários, por insetos ou por contato casual. Embora o vírus HIV tenha sido isolado na saliva, há fortes evidências contra a transmissão através do beijo.

A transferência de sangue de uma pessoa infectada com HIV para uma outra pessoa tem sido claramente estabelecido como um modo de transmissão. Outras fontes de infecção com HIV nesta categoria são os órgãos transplantados tais como rins e sêmen para inseminação artificial.

Há indicações de que a transmissibilidade da infecção com HIV varie grandemente durante o curso da infecção em um indivíduo. A transmissão pode ser mais provável logo após a infecção e antes do corpo desenvolver uma resposta via anticorpos. Como o nível de vírus HIV no sangue diminui durante o período assintomático, a transmissibilidade parece ser menor neste período. Então a transmissibilidade parece aumentar novamente assim que a contagem das células CD4 diminui e o nível do vírus no sangue aumenta, surgindo assim os sintomas da AIDS.

Cepas do HIV são molecularmente e biologicamente heterogêneas, com algumas cepas sendo mais virulentas. Além disso, o vírus HIV pode mudar rapidamente, até mesmo dentro de um indivíduo. O HIV infecta principalmente uma subpopulação de linfócitos T chamados de linfócitos CD4 ou células T4, que são as estrategistas da defesa imunológica: recebem informações sobre como reconhecer o invasor e comandam as células matadoras para a ação, contra as invasoras. O HIV invade uma célula CD4 e pode permanecer dormente por um longo tempo. As células CD4 são eventualmente mortas pelo HIV enquanto o HIV se reproduz, de modo que o número de células CD4 diminui gradualmente do número normal de aproximadamente $900 / \mathrm{ml}$. Isso conduz a várias imunodeficiências na pessoa infectada com HIV. Assim a história natural da infecção com HIV é uma gradual depleção das células CD4, uma progressiva falta de resposta do sistema imune e conseqüente aumento de suscetibilidade a infeç̧ões oportunísticas tais como Pneumocystis carinii pneumonia (PCP) e uma forma rara de câncer denominada sarcoma de Kaposi.

Existem diferentes manifestações clínicas da infecção com HIV e AIDS. Em alguns pacientes ocorre uma infecção aguda com HIV logo após a infecção 
caracterizada por uma febre intensa, suores, letargia, dores musculares, dores de cabeça e garganta. Esses sintomas podem durar de 2 a 3 semanas. Aproximadamente 2 meses após a infecção, o sistema imune gera anticorpos que são reconhecidos pelo teste ELISA (enzyme-linked imunoassay). Após um período assintomático de aproximadamente 5 anos, uma pessoa infectada com HIV pode desenvolver alguns sintomas tais como candidíase oral, herpes zoster, perda de peso, diarréia, doenças neurológicas (demência, mielopatia, polineuropatia) e tuberculose. A pessoa infectada com HIV pode morrer de uma dessas doenças, mas freqüentemente uma ou mais infecções oportunísticas ou neoplasmas que caracterizam a AIDS acometem a pessoa. Entre essas doenças incluem-se infecção por citomegalovirus, Pneumocystis Carinii pneumonia, toxoplasmose do cérebro e sarcoma de Kaposi. A definição original de AIDS foi revisada em 1985 e novamente alterada em 1987. Atualmente a definição inclui as pessoas com a contagem de células CD4 abaixo de $200 / \mathrm{ml}$ o que praticamente dobrou o número de pessoas satisfazendo a definição de AIDS.

\subsection{Modelando a Progressão de Pessoas com HIV à AIDS}

O período de incubação da AIDS é o tempo desde a infecção com HIV até o desenvolvimento da AIDS. O período latente (isto é, da infecção até a infecciosidade) para a infecção com HIV é suficientemente curta para ser ignorada no modelo. O período infeccioso é desconhecido, mas o vírus parece persistir no hospedeiro indefinidamente já que pode ser isolado do sangue muitos anos após a infecção. Nenhuma evidência do contrário existe, assim a infectividade do HIV é assumida contínua por toda vida. Como os indivíduos são ou suscetíveis à infecção com HIV ou infecciosos então a AIDS é uma doença do tipo SIR (suscetível-infectado-removido).

Pessoas que estão infectadas com HIV parecem progredir através de vários estágios ou fases rumo à AIDS e morrer devido à AIDS. Um modelo natural para essa progressão é através de uma seqüência de cinco fases baseadas em sintomas clínicos. A primeira fase é o período pré-anticorpo, na qual a pessoa está infectada mas não apresenta anticorpos soropositivos. Algumas pessoas nesta fase apresentam doenças agudas. A segunda fase inclui pessoas que estão infectadas e apresentam anticorpos soropositivos mas são 
assintomáticas. A terceira fase (sintomática) ocorre quando a pessoa desenvolve um anormal indicador hematológico e uma enfermidade inicial tal como uma persistente linfoadenopatia ou candidiase oral. A quarta fase é a AIDS clínica e a quinta fase é a morte devido à AIDS.

As fases sintomáticas e assintomáticas são subdividas em estágios para fornecer uma maior flexibilidade ao modelo.

À medida que informações sobre os efeitos do HIV sobre o sistema imune foram se acumulando, tornou-se claro que o progresso em direção à AIDS coincide com o declínio no número de linfócitos CD4. Assim é lógico usar esse declínio como um modelo de progressão por estágios. Dessa maneira, intervalos para os valores de linfócitos C.D4 podem ser usados como estágios e a progressão através desses estágios podem ser medidas.

Esses modelos de progressão por estágios são mostrados na Fig. 3.1 para $m=7$, onde $m$ é o número de estágios infecciosos.

O modelo de progressão baseado na contagem de linfócitos CD4 é mais preciso do que o modelo de progressão baseado em sintomas clínicos já que envolve medidas laboratoriais quantitativas. Eles são normalmente usados como indicadores de início de tratamento e provavelmente se tornarão mais amplamente utilizados como marcadores da progressão da infecção com HIV.

Recentemente a contagem viral tem sido utilizada como um outro indicador da progressão da infecção com HIV, sendo que algumas drogas conseguem reduzir dramaticamente a carga viral na maioria das pessoas infectadas, às vezes a níveis impossíveis de detecção no sangue. 


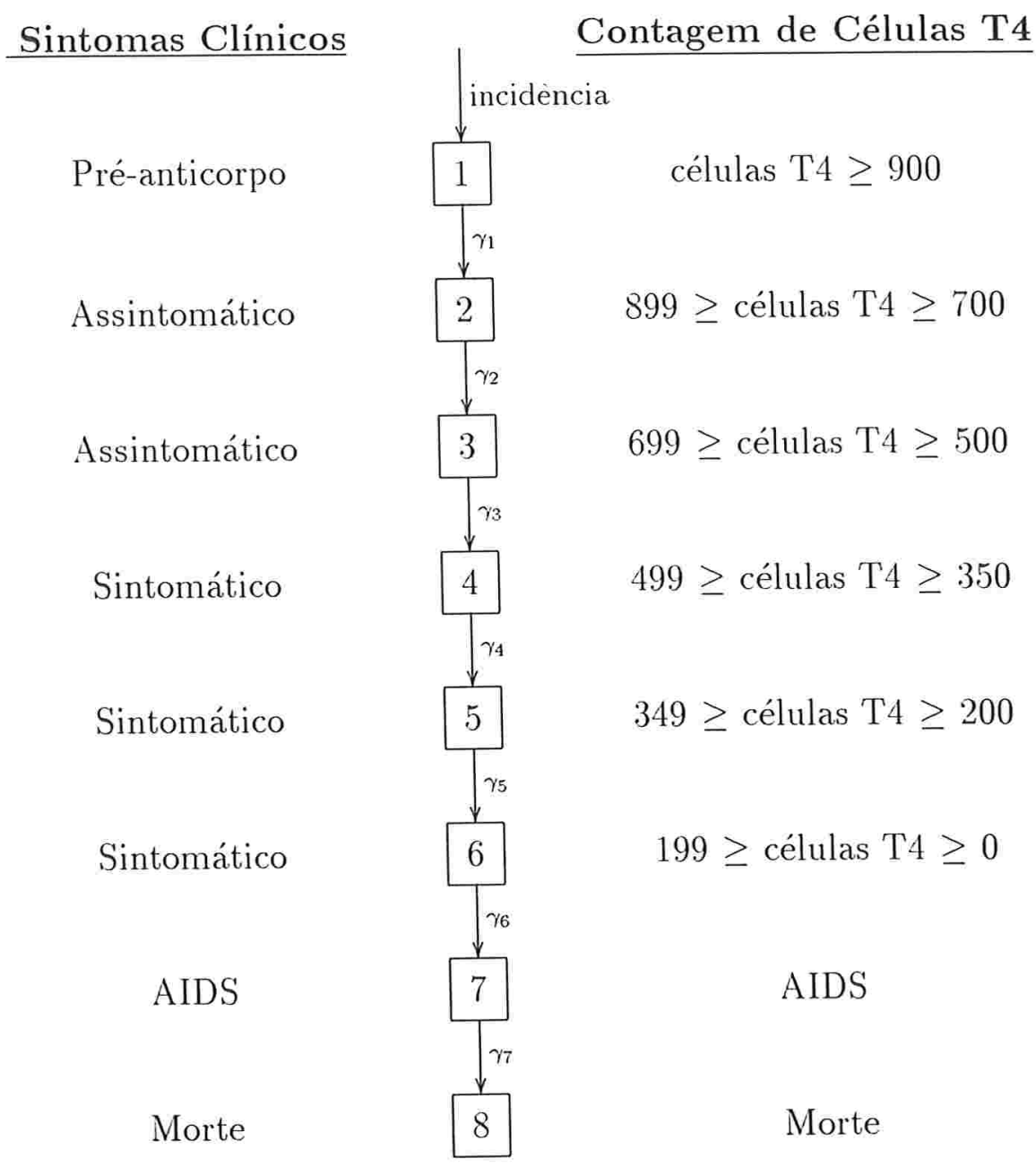

Fig. 3.1 O modelo de estágios baseado em indicadores clínicos ou por contagem de células T4 para progressão à AIDS e morte quando existem 7 estágios infecciosos (6 estágios antes da AIDS). 


\subsection{Formulação do Modelo}

Considere o diagrama de fluxos mostrado na Fig. 3.2. A população considerada aqui consiste de pessoas sexualmente ativas. $\mathrm{O}$ número $m$ de estágios infecciosos mostrado na Fig. 3.2 é quatro por simplicidade e o tamanho da população é constante e igual a $N$. No compartimento $Y_{0}$ estão as pessoas suscetiveis e os cinco compartimentos $Y_{i}, i=1, \ldots, 5$, correspondem aos quatro estágios na progressão à AIDS e morte. O compartimento $Y_{5}$ contém indivíduos que morreram de AIDS. Como pessoas que morreram de AIDS estão incluídas no tamanho da população, a fração dessas populações que ainda estão vivas e sexualmente ativas decrescem à medida que mais pessoas morrem.

Mortes naturais (não relacionadas com a infecção com HIV) ocorrem em cada compartimento a mesma taxa $\mu$ que é balanceada com a entrada $\mu N$ no compartimento dos suscetíveis.

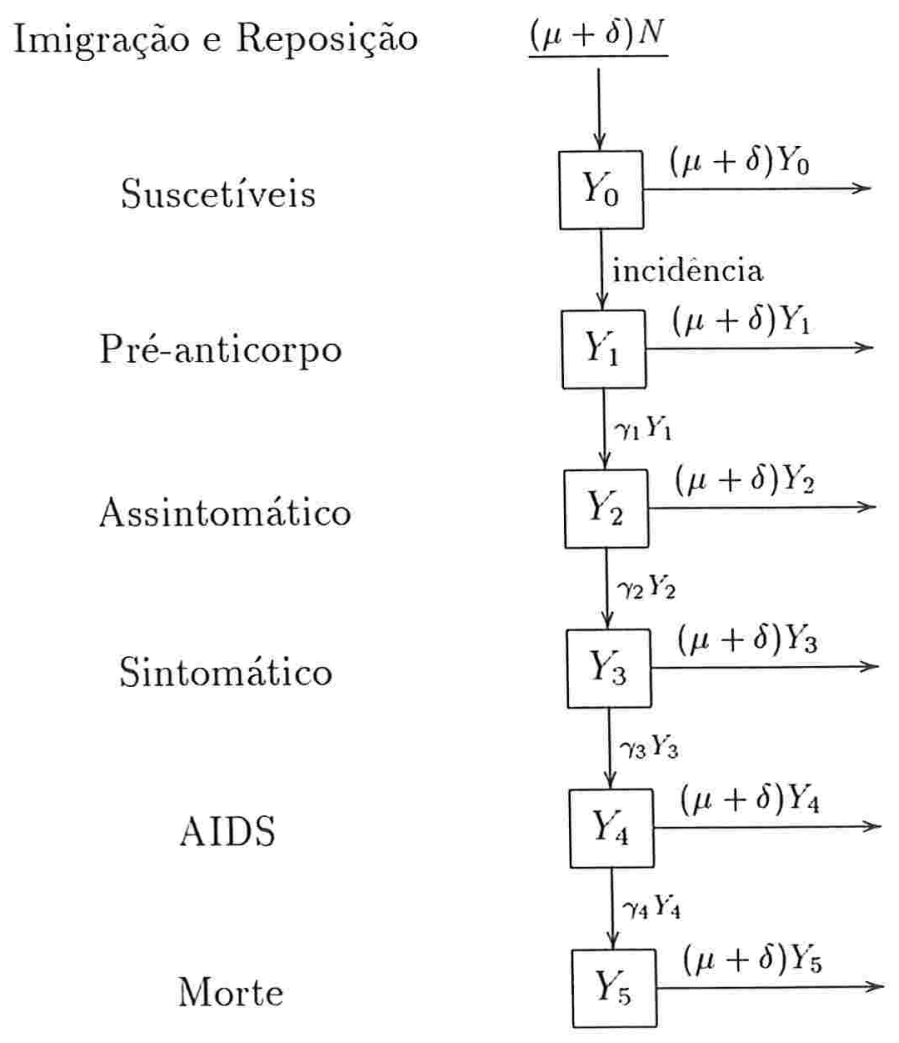

Fig. 3.2 Diagrama do modelo com compartimentos e transferências. 
A taxa de transferência constante $\delta$ corresponde a migração normal de pessoas sexualmente ativas. As emigrações dos compartimentos são balanceadas pela imigração $\delta N$ no compartimento dos suscetiveis.

Os parâmetros $\gamma_{1}, \gamma_{2}, \gamma_{3}$ e $\gamma_{4}$ na Fig. 3.2 governam os movimentos através dos estágios da infecção com HIV à AIDS e morte devidos a AIDS. Essas taxas de transferências constantes correspondem ao tempo de espera da exponencial negativa nos compartimentos e com tempo de espera médio igual a $1 / \gamma_{1}, 1 / \gamma_{2}, 1 / \gamma_{3}$ e $1 / \gamma_{4}$, respectivamente.

\subsection{Análise Matemática do Modelo}

A população é suposta homogênea, ou seja, os indivíduos apresentam os mesmos comportamentos sexuais e se relacionam uniformemente.

Seja $Y_{k}$ o número de pessoas no estágio $k$, onde estágio 0 é o compartimento das pessoas suscetíveis, no estágio 1, pessoas estão no estágio infeccioso e assim por diante. No estágio $m$, pessoas estão com AIDS e no estágio $m+1$ estão as pessoas que morreram devido à AIDS. Assim, com $N$ sendo o número (constante) de pessoas da população, as variáveis $Y_{0}, Y_{1}, Y_{2}, \ldots, Y_{m+1}$ satisfazem

$$
Y_{0}+Y_{1}+\cdots+Y_{m+1}=N \text {. }
$$

Seja $\lambda_{j}, j=1,2, \ldots, m$ o número médio de contatos sexuais que uma pessoa infectada do estágio $j$ tem com todas as pessoas e que são suficientes para causar infeç̧ão com HIV em pessoas suscetíveis.

O sistema de equações diferenciais correspondente ao modelo da Fig. 3.2 é:

$$
\left\{\begin{array}{l}
Y_{0}^{\prime}=(\delta+\mu)\left(N-Y_{0}\right)-\frac{Y_{0} \sum_{j=1}^{m} \lambda_{j} Y_{j}}{\sum_{k=0}^{m} Y_{k}} \\
Y_{1}^{\prime}=\frac{Y_{0} \sum_{j=1}^{m} \lambda_{,} Y_{j}}{\sum_{k=0}^{m} Y_{k}}-\left(\delta+\mu+\gamma_{1}\right) Y_{1}, \\
Y_{k}^{\prime}=\gamma_{k-1} Y_{k-1}-\left(\delta+\mu+\gamma_{k}\right) Y_{k}, 2 \leq k \leq m+1,
\end{array}\right.
$$

onde " $"$ " denota a derivada com respeito ao tempo e $\gamma_{m+1}=0$. 
Em (3.1) o termo $-(\delta+\mu) Y_{k}$ representa a emigração e mortes naturais, enquanto $(\delta+\mu) N$ representa a imigração e outras entradas para compensar as perdas.

O termo relativo à incidência é a fração de suscetíveis multiplicada pela soma do produto entre as taxas de contato $\left(\lambda_{j}\right)$ e o número de infectados nos respectivos estágios. O modelo (3.1) pode ser simplificado convertendo-se os número nos estágios em frações. Seja $I_{j}=Y_{j} / N$ a fração da população no estágio infeccioso $j, 0 \leq j \leq m+1$.

$\mathrm{O}$ modelo pode então ser descrito pelas equaçòes:

$$
\left\{\begin{array}{l}
I_{1}^{\prime}=g(I) I_{0}-\xi_{1} I_{1} \\
I_{k}^{\prime}=\gamma_{k-1} I_{k-1}-\xi_{k} I_{k}, 2 \leq k \leq m+1
\end{array}\right.
$$

onde

$$
g(I)=\frac{\sum_{j=1}^{m} \lambda_{j} I_{j}}{1-I_{m+1}}, \xi_{k}=\left(\delta+\mu+\gamma_{k}\right), \gamma_{m+1}=0 \text { e } I_{0}=1-\sum_{j=1}^{m+1} I j .
$$

Examinando (3.2), podemos observar que o conjunto

$$
\mathcal{D}=\left\{\left(I_{1}, \ldots, I_{m+1}\right) \in \mathbb{R}_{+}^{m+1}: I_{1}+\cdots+I_{m+1} \leq 1\right\}
$$

é positivamente invariante. O lado direito de (3.2) satisfaz uma condição de Lipschitz para $I_{m+1}<1$, de modo que existe uma única solução do problema de valor inicial definida no intervalo maximal $[0, \infty[$ e que está contida no conjunto $\mathcal{D}$. Assim o problema de valor inicial é bem-posto.

Existem dois possíveis pontos de equilíbrio para o sistema (3.2): o trivial ou equilíbrio livre de doença (DFE) e um equilíbrio endêmico (EE) que é mostrado explicitamente abaixo. O DFE, com $I_{0}=1$ e $I_{k}=0$ para $1 \leq k \leq$ $m+1$, está sempre no conjunto $\mathcal{D}$. O EE abaixo está em $\mathcal{D}$ quando os valores dos parâmetros satisfazem a condição de estarem acima do limiar.

Para obter o EE, tomamos a $(m+1)$-ésima equação de equilíbrio e a resolvemos iterativamente em função de $I_{m+1}$ obtendo:

$$
I_{k}=I_{m+1} \prod_{j=k}^{m} \xi_{j+1} / \gamma_{j}, 1 \leq k \leq m \text {. }
$$


A equação $I_{1}^{\prime}=0$ fornece $I_{0}$ em termos de valores de outros $I_{k}$, usando (3.4) e simplificando obtemos:

$$
\begin{aligned}
I_{0} & =\frac{\xi_{1} I_{1}}{g(I)} \\
& =\frac{\left(1-I_{m+1}\right)}{\sum_{j=1}^{m} \lambda_{j} I_{j}} \xi_{1} I_{1} \\
& =\frac{\left(1-I_{m+1}\right)}{\sum_{j=1}^{m} \lambda_{j} \prod_{k=j}^{m}\left(\xi_{k+1} / \gamma_{k}\right)} \frac{\prod_{j=1}^{m+1} \xi_{j}}{\prod_{j=1}^{m} \gamma_{j}}
\end{aligned}
$$

Portanto

$$
I_{0}=\frac{\left(1-I_{m+1}\right)}{\sum_{j=1}^{m}\left(\lambda_{j} / \xi_{j}\right) \prod_{k=1}^{j-1} \gamma_{k} / \xi_{k}}
$$

Usando que $I_{0}+\cdots+I_{m+1}=1$, o termo $I_{m+1}$ no equilíbrio endêmico satisfaz:

$$
I_{m+1}^{e}=\frac{\left(\sum_{j=1}^{m}\left(\lambda_{j} / \xi_{j}\right) \prod_{k=1}^{j-1} \gamma_{k} / \xi_{k}\right)-1}{\left(\sum_{j=1}^{m}\left(\lambda_{j} / \xi_{j}\right) \prod_{k=1}^{j-1} \gamma_{k} / \xi_{k}\right)\left(1+\sum_{j=1}^{m}\left(\prod_{k=j}^{m} \xi_{k+1} / \gamma_{k}\right)\right)-1}
$$

Usando $I_{m+1}^{e}$ dado em (3.6), os valores $I_{k}^{e}$ e $I_{0}^{e}$ são dados por (3.4) e (3.5). Definimos o número de contato $\sigma$ como:

$$
\sigma=\sum_{j=1}^{m}\left(\lambda_{j} / \xi_{j}\right) \prod_{k=1}^{j-1} \gamma_{k} / \xi_{k}
$$

Nas seções seguintes mostraremos que o número de contato $\sigma$ dado por (3.7) é a quantidade limiar que determina se a doença se extingue $(\sigma \leq 1)$ ou se permanece epidêmica $(\sigma>1)$. Como o número de contato $\sigma$ é o número médio de novos infectivos produzidos por um infectivo durante seu estágio 
infeccioso em uma populaçào totalmente suscetivel. ele é algumas vezes chamado de número reprodutivo básico. É intuitivamente razoável que se $\sigma<1$ então cada infectivo é substituído por menos do que um novo infectivo de modo que a doença se extingüe (o DFE é assintoticamente estável). Entretanto, se $\sigma>1$ de modo que a infectividade média em uma populaçào totalmente suscetivel é substituída por mais do que um novo infectivo, então a doença deve persistir (o DFE é instável). Nas seções seguintes mostraremos que, sob algumas hipóteses, quando $\sigma>1$ a doença persiste, há um único equilíbrio endêmico e todas as soluções se aproximam do equilíbrio endênico.

Lema 3 Sé $\sigma>1$ então o equilíbrio endêmico dado por (3.6) e (3.4) é um equilíbrio distinto em $\mathcal{D}$ e é o único equilíbrio $\mathrm{em} \mathcal{D}$ além do DFE.

\section{Prova:}

Se $\sigma>1$ então, por (3.6), é fácil ver que $0<I_{m+1}^{e}<1$. Assim, todo $I_{k}^{e}$ é positivo para $0 \leq k \leq m$ por (3.4) e (3.5). Como a soma dos valores $I_{k}^{e}$ é igual a 1 então cada um deles deve ser menor que 1 e esse equilíbrio é um equilíbrio endêmico e está em $\mathcal{D}$. Se $\sigma=1$ então o EE dado por (3.6) e (3.4) é o DFE. Quando $\sigma<1$ o ponto de equilíbrio não está em $\mathcal{D}$.

\subsubsection{Estabilidade do Equilíbrio Livre de Doença DFE}

A estabilidade local e global do DFE será analisada agora. Lembremos que a incidência $\mathcal{I}$ é dada por:

$$
\mathcal{I}=g(I) I_{0}=\left(\sum_{j=1}^{m} \lambda_{j} I_{j}\right)\left(1-\sum_{k=1}^{m+1} I_{k}\right)\left(1-I_{m+1}\right)^{-1} .
$$

O segundo e terceiro fatores de $\mathcal{I}$ são:

$\left(1-\sum_{k=1}^{m+1} I_{k}\right)\left(1+I_{m+1}+I_{m+1}^{2}+\cdots\right)=\left(1-\sum_{k=1}^{m} I_{k}-I_{m+1} \sum_{k=1}^{m} I_{k}-I_{m+1}^{2} \sum_{k=1}^{m} I_{k}-\cdots\right)$

de modo que

$$
\mathcal{I}=\sum_{j=1}^{m} \lambda_{j} I_{j}-G(I)
$$

onde

$$
G(I)=\left(\sum_{j=1}^{m} \lambda_{j} I_{j}\right)\left(\sum_{i=1}^{m} I_{i}\right)\left(\sum_{k=0}^{\infty} I_{m+1}^{k}\right)
$$


e $G(I)$ é $o(I)$, isto é. $\lim _{I \rightarrow 0} \frac{C_{I}(I)}{|I|}=0$. Assim para linearizar o modelo, substituímos o termo $\mathcal{I}$ por $\mathcal{I}_{L}=\sum_{j=1}^{m} \lambda_{j} I_{j}$. Para checar a estabilidade da linearização, definimos $I=\left(I_{1}, I_{2}, \ldots, I_{m+1}\right)^{T}, G(I)$ como acima e a matriz $A_{(m+1 \times m+1)}$ como

$$
A=\left[\begin{array}{cccccc}
\lambda_{1}-\xi_{1} & \lambda_{2} & \lambda_{3} & \ldots & \lambda_{m} & 0 \\
\gamma_{1} & -\xi_{2} & 0 & \ldots & 0 & 0 \\
0 & \gamma_{2} & -\xi_{3} & \ldots & 0 & 0 \\
\vdots & \vdots & & & & \vdots \\
0 & 0 & \ldots & & \gamma_{m} & -\xi_{m+1}
\end{array}\right]
$$

O modelo (3.2) torna-se:

$$
I^{\prime}=A I-(G(I), 0, \ldots, 0)^{T} .
$$

A linearização resulta em:

$$
I^{\prime}=A I .
$$

A estabilidade local do DFE é determinada pela análise do autovalores de $A$ no DFE.

Lema 4 Para a matriz A acima, o autovalor com maior parte real é um autovalor real algebricamente simples.

\section{Prova:}

Seja $E_{k}$ a matriz identidade $k \times k$. Então a equação característica de $A$ é $\left|\alpha E_{m+1}-A\right|=\left(\alpha+\xi_{m+1}\right)\left|\alpha E_{m}-A_{m}\right|$, onde $A_{m}$ é a matriz $m \times m$ obtida suprimindo-se a última linha e a última coluna de $A$. Um autovalor de $A$ é $\alpha=-\xi_{m+1}=-(\delta+\mu)<0$ e os outros são os autovalores de $A_{m}$. Definimos o módulo de estabilidade $s(A)$ como o máximo da parte real dos autovalores de $A$ e o raio espectral $\rho(A)$ como o máximo do valor absoluto dos autovalores de $A$. Seja $\tau=\max \left\{\xi_{1}-\lambda_{1}, \xi_{2}, \xi_{3}, \ldots, \xi_{m}\right\}+1$ e $B=A_{m}+\tau E_{m}$. Então $B$ é uma matriz não negativa com autovalores $\beta_{k}=\left(\alpha_{k}+\tau\right), k=1, \ldots, m$, onde $\left\{\alpha_{1}, \alpha_{2}, \ldots, \alpha_{m}\right\}$ são os autovalores de $A_{m}$. Como a infecção em qualquer estágio $I_{k}$ pode se propagar por toda população então a matriz $A_{m}$ e também a matriz $B$ são irredutíveis. Como $B$ é irredutivel e não negativa, pelo Teorema 8 do Apêndice, $\rho(B)=s(B)$ é um autovalor de $B$ qué é real, geometricamente e algebricamente simples e existe um autovetor positivo $\omega$ associado a $s(B)$. Assim, $s\left(A_{m}\right)=(s(B)-\tau)$ é um autovalor real e simples de $A$. 
Lema 5 Os autovalores da matriz $A_{m}$ acima são raízes da equação característica $p_{m}(\alpha)=\operatorname{det}\left(\alpha E_{m}-A_{m}\right)$, onde

$$
\begin{aligned}
p_{m}(\alpha) & =\prod_{j=1}^{m}\left(\xi_{j}+\alpha\right)-\sum_{k=1}^{m} \lambda_{k} \prod_{j=1}^{k-1} \gamma_{i} \prod_{i=k+1}^{m}\left(\xi_{i}+\alpha\right) \\
& =\left(\prod_{j=1}^{m}\left(\xi_{j}+\alpha\right)\right)\left(1-\sum_{k=1}^{m} \frac{\lambda_{k}}{\xi_{k}+\alpha} \prod_{i=1}^{k-1} \frac{\gamma_{i}}{\xi_{i}+\alpha}\right),
\end{aligned}
$$

$\operatorname{com} \prod_{j=1}^{0}(\cdot)=1$

\section{Prova:}

A prova é por indução sobre $m$. Observemos que:

$$
\left|\alpha E_{2}-A_{2}\right|=\left|\begin{array}{cc}
\alpha+\xi_{1}-\lambda_{1} & -\lambda_{2} \\
-\gamma_{1} & \alpha+\xi_{2}
\end{array}\right|,
$$

isto é,

$$
\left|\alpha E_{2}-A_{2}\right|=\left(\alpha+\xi_{1}\right)\left(\alpha+\xi_{2}\right)-\lambda_{1}\left(\alpha+\xi_{2}\right)-\lambda_{2} \gamma_{1},
$$

assim, (3.11) é verdadeira para $m=2$.

Assumiremos que a hipótese de indução é verdadeira para $m$.

Entiào

$$
\left|\alpha E_{m+1}-A_{m+1}\right|
$$

é igual a

$$
\left|\begin{array}{cccccc}
\alpha+\xi_{1}-\lambda_{1} & -\lambda_{2} & -\lambda_{3} & \cdots & -\lambda_{m} & -\lambda_{m+1} \\
-\gamma_{1} & \alpha+\xi_{2} & 0 & \cdots & 0 & 0 \\
0 & -\gamma_{2} & \alpha+\xi_{3} & \cdots & 0 & 0 \\
\vdots & \vdots & & \ddots & \vdots & \vdots \\
0 & 0 & \ldots & -\gamma_{m-1} & \alpha+\xi_{m} & 0 \\
0 & 0 & \cdots & 0 & -\gamma_{m} & \alpha+\xi_{m+1}
\end{array}\right| .
$$

Expandindo em torno da última coluna obtemos:

$$
\begin{aligned}
\left|\alpha E_{m+1}-A_{m+1}\right| & =(-1)^{m+1} \lambda_{m+1} \prod_{j=1}^{m}\left(-\gamma_{j}\right)+\left(\alpha+\xi_{m+1}\right) p_{m}(\alpha) \\
& =-\lambda_{m+1} \prod_{j=1}^{m} \gamma_{j}+\prod_{j=1}^{m+1}\left(\xi_{j}+\alpha\right)-\sum_{k=1}^{m} \lambda_{k} \prod_{j=1}^{k-1} \gamma_{j} \prod_{i=k+1}^{m+1}\left(\xi_{i}+\alpha\right)
\end{aligned}
$$




$$
\begin{aligned}
& =\prod_{j=1}^{m+1}\left(\xi_{j}+\alpha\right)-\sum_{k=1}^{m+1} \lambda_{k} \prod_{j=1}^{k-1} \gamma_{j} \prod_{i=k+1}^{m+1}\left(\xi_{i}+\alpha\right) \\
& =p_{m+1}(\alpha) .
\end{aligned}
$$

Notemos que:

$$
p_{m}(0)=\prod_{j=1}^{m} \xi_{j}-\sum_{k=1}^{m} \lambda_{k} \prod_{j=1}^{k-1} \gamma_{j} \prod_{i=k+1}^{m} \xi_{i}, \text { e }\left|A_{m}\right|=(-1)^{m} p_{m}(0) .
$$

Pelo Lema $4, s(A)$ é o autovalor simples com maior parte real positiva (ou com menor parte real negativa) raiz de $p_{m}$, assim, se $s(A)<0$ então todos os autovalores de $A$ tem parte real negativa, e se $s(A)>0$, pelo menos um autovalor de $A$ tem parte real positiva. No primeiro caso, o DFE é localmente assintoticamente estável e no segundo caso. é instável. Do Teorema 5 abaixo obtemos uma condição de limiar sobre esta propriedade.

Lema 6 Sejam $p_{m}$ dado por (3.11) e $\sigma$ dado por (3.7). Então $\sigma<1$ implica que $p_{m}$ não tem raízes reais não negativas.

\section{Prova:}

Notemos que:

$$
p_{n}(\alpha)=\left(\xi_{n}+\alpha\right) p_{n-1}(\alpha)-\lambda_{n} \prod_{j=1}^{n-1} \gamma_{j}
$$

de modo que $p_{n}^{\prime}=p_{n-1}+\left(\xi_{n}+\alpha\right) p_{n-1}^{\prime}$. A prova é por indução sobre $p_{n}(0)>0$ e $p_{n}^{\prime}(\alpha)>0$ para $\alpha>0$ e $1 \leq n \leq m$. Para $n=1, \sigma<1$ implica que $\lambda_{1}-\xi_{1}<0$. Então $p_{1}(0)=-\lambda_{1}+\xi_{1}>0$, e $p_{1}^{\prime}=1>0$, portanto a hipótese de indução é verdadeira para $n=1$.

Assumiremos agora que a hipótese de indução é verdadeira para $n \leq m-1$. Assim, $\sigma<1$ para $n+1$ implica

$$
p_{n+1}(0)=\prod_{j=1}^{n+1} \xi_{j}\left(1-\sum_{k=1}^{n+1}\left(\lambda_{k} / \xi_{k}\right) \prod_{j=1}^{k-1} \gamma_{j} / \xi_{j}\right)>0 .
$$

Logo, $p_{n+1}^{\prime}(\alpha)=p_{n}(\alpha)+\left(\xi_{n+1}+\alpha\right) p_{n}^{\prime}(\alpha)>0$ para $\alpha>0$, já que $p_{n}(\alpha)>0$ e $p_{n}^{\prime}(\alpha)>0$ para $\alpha>0$.

Assim a hipótese de indução é verdadeira para $m$ de modo que $p_{m}$ não tem raizes reais não negativas. 
Teorema 5 Seja o dado por (3.7). Entào o DFE para o modelo (3.2) é localmente assintoticamente estável se $\sigma<1$. e o DFE é instável se $\sigma>1$.

\section{Demonstração:}

O polinômio característico é $|\alpha E-A|=\left(\xi_{m+1}+\alpha\right) p_{m}(\alpha)=0$. Notemos que $|\alpha E-A|$ é um polinômio em $\alpha$ com o coeficiente do polinômio de maior grau igual a 1 , de modo que quando $a \rightarrow \infty,|\alpha E-A| \rightarrow \infty$.

Avaliando $|\alpha E-A|$ em $\alpha=0$ obtemos $\prod_{j=1}^{m+1} \xi_{j}(1-\sigma)$, que tem o mesmo sinal que $1-\sigma$.

Assim, se $1-\sigma<0$ existe $\hat{\alpha}>0$ tal que $|\hat{\alpha} E-A|=0$, de modo que $\hat{\alpha}$ é um autovalor real de $A$, e o DFE é instável. Por outro lado, se $\sigma<1$, o Lema 6 implica que $p_{m}$ não tem raízes reais para $\alpha \geq 0$, e a raiz restante é $\alpha=-\xi_{m+1}=-(\delta+\mu)<0$. Assim, o Lema 4 prova que $s(A)$, o autovalor de $A$ com maior parte real, é real. O argumento acima prova que $s(A)<0$, de modo que DFE é localmente assintoticamente estável.

Teorema 6 Para $\sigma \leq 1$, o DFE para o modelo (3.2) é globalmente assintoticamente estável.

\section{Demonstração:}

A matriz transposta da matriz $A_{m}$, como definida no Lema 4, é irredutível com elementos não negativos fora da diagonal principal, assim, existe um autovetor positivo $\eta=\left(\eta_{1}, \eta_{2}, \ldots, \eta_{m}\right)$ associado ao autovalor $s\left(A_{m}^{T}\right)$. Seja $w=\left(\eta_{1}, \eta_{2}, \ldots, \eta_{m}, 0\right)$, então $A^{T} w=s\left(A_{m}^{T}\right) w$ e notemos que, da prova do Teorema $5, \sigma \leq 1$ é equivalente a $s(A) \leq 0$, logo $s\left(A_{m}^{T}\right) \leq s\left(A^{T}\right) \leq 0$.

Como no Capítulo 1 , consideremos a função de Liapounov $V: \mathbb{R}^{m+1} \rightarrow \mathbb{R}$ dada por $V(I)=\langle w, I\rangle$ com derivada dada por:

$$
\begin{aligned}
V^{\prime}(I)= & \left\langle w, I^{\prime}\right\rangle \\
= & \left.<w, A I-(G(I), 0, \ldots, 0)^{T}\right\rangle \\
= & \left.<A^{T} w, I\right\rangle-w_{1} G(I) \\
= & \left.s\left(A_{m}^{T}\right)<w, I\right\rangle-w_{1} G(I) \leq 0 .
\end{aligned}
$$

Pelo Princípio da Invariância de La Salle (ver Apêndice), todas soluções se aproximam do maior subconjunto invariante do conjunto $M$ na qual $V^{\prime}=0$. Para a função de Liapounov acima, esse subconjunto $M$ é a origem, assim todas as soluções se aproximam do DFE, onde $I_{k}$ é zero para $1 \leq k \leq m+1$. 


\subsubsection{Estabilidade do Equilíbrio Endêmico EE}

O artigo de Herbert W. Hethcote e James W. van Ark (1992), na qual esse capítulo se baseia, apresenta uma demonstração incorreta da estabilidade local do equilíbrio endêmico. Demonstramos abaixo este resultado com algumas hipóteses adicionais.

Teorema 7 Se $\sigma>1$ então o equilíbrio endêmico de (3.2) é localmente assintoticamente estável se:

a) $m \leq 2$ ou

b) $m \in \mathbb{N}^{*}, \tau_{i}>0, \forall i=2, \ldots, m e$

$$
\begin{gathered}
(\sigma-\sigma \theta-1)<0, \\
\text { onde } \theta=\sum_{k=1}^{m} \theta_{k}, \theta_{k}=\prod_{j=k}^{m} \xi_{j+1} / \gamma_{j} \text { e } \tau_{i}=\left(\lambda_{i} / \sigma\right)-g(I) \text { para } 1 \leq i \leq m .
\end{gathered}
$$

\section{Demonstração:}

A matriz Jacobiana de (3.2) quando avaliada no EE dado por (3.4) e (3.6) é

$$
B=\left[\begin{array}{cccccc}
\tau_{1}-\xi_{1} & \tau_{2} & \tau_{3} & \ldots & \tau_{m} & \tau_{m+1} \\
\gamma_{1} & -\xi_{2} & 0 & \ldots & 0 & 0 \\
0 & \gamma_{2} & -\xi_{3} & \ldots & 0 & 0 \\
\vdots & \vdots & & & & \vdots \\
0 & 0 & \ldots & & \gamma_{m} & -\xi_{m+1}
\end{array}\right]
$$

onde $\tau_{i}=\left(\lambda_{i} / \sigma\right)-g(I)$ para $1 \leq i \leq m$ e $\tau_{m+1}=((1 / \sigma)-1) g(I)$. Da prova do Lema 5 , obtemos a equação característica associada à matriz $B$ :

$$
|\alpha E-B|=q_{m+1}(\alpha)=0 \text {, }
$$

onde $q_{m+1}$ é o igual a $p_{m+1}$ definido em (3.11) com $\tau_{k}$ no lugar de $\lambda_{k}$.

Para $n=1, q_{1}(\alpha)=\alpha-\tau_{1}+\xi_{1}$, assim:

$$
q_{1}(0)=\xi_{1}\left[1-\left(\lambda_{1} / \xi_{1}\right) / \sigma\right]+g(I)>0,
$$

pois $\sigma>\lambda_{1} / \xi_{1}$ por (3.7).

De (3.12) podemos concluir que:

$$
q_{n+1}(\alpha)=\left(\xi_{n+1}+\alpha\right) q_{n}(\alpha)-\tau_{n+1} \prod_{j=1}^{n} \gamma_{j},
$$


donde segue, por indução, que todos os coeficientes dos $q_{n}$ são positivos, $\forall n \in \mathbb{N}$, já que $q_{1}(0)>0$ por (3.14).

Para o caso a) usaremos o Teorema de Routh-Hurwitz (ver Teorema 10 do Apêndice).

Se $m=1$ temos que:

$$
\begin{aligned}
q_{2}(\alpha) & =\left(\alpha+\xi_{2}\right)\left(\alpha-\tau_{1}+\xi_{1}\right)-\tau_{2} \gamma_{1} \\
& =\alpha^{2}+\left(\xi_{1}+\xi_{2}-\tau_{1}\right) \alpha+\xi_{1} \xi_{2}-\tau_{1} \xi_{2}-\tau_{2} \gamma_{1} \\
& =\alpha^{2}+b_{1} \alpha+b_{0},
\end{aligned}
$$

onde $b_{1}=\xi_{1}+\xi_{2}-\tau_{1}$ e $b_{0}=\xi_{1} \xi_{2}-\tau_{1} \xi_{2}-\tau_{2} \gamma_{1}$.

Em vista das considerações acima podemos concluir que $b_{1}$ e $b_{0}$ são positivos e portanto $q_{2}$ é um polinômio estável (a parte real dos autovalores é negativa), pois um polinômio de segundo grau é estável se e somente se todos seus coeficientes são positivos.

Se $m=2$ então

$$
\begin{aligned}
q_{3}(\alpha) & =\left(\alpha+\xi_{3}\right)\left(\alpha^{2}+b_{1} \alpha+b_{0}\right)-\tau_{3} \gamma_{1} \gamma_{2} \\
& =\alpha^{3}+\left(b_{1}+\xi_{3}\right) \alpha^{2}+\left(b_{0}+\xi_{3} b_{1}\right) \alpha+\xi_{3} b_{0}-\gamma_{1} \gamma_{2} \tau_{3} \\
& =\alpha^{3}+a_{2} \alpha^{2}+a_{1} \alpha+a_{0},
\end{aligned}
$$

onde $a_{0}=\xi_{3} b_{0}-\gamma_{1} \gamma_{2} \tau_{3}, a_{1}=b_{0}+\xi_{3} b_{1}$ e $a_{2}=b_{1}+\xi_{3}$.

A matriz de Routh-Hurwitz é:

$$
\begin{aligned}
H_{3} & =\left[\begin{array}{ccc}
a_{2} & a_{0} & 0 \\
1 & a_{1} & 0 \\
0 & a_{2} & a_{0}
\end{array}\right] \\
& =a_{0} H_{2},
\end{aligned}
$$

onde $a_{0}, a_{1}, a_{2}$ são positivos e

$$
\begin{aligned}
H_{2} & =\left[\begin{array}{cc}
a_{2} & a_{0} \\
1 & a_{1}
\end{array}\right] \\
& =\left[\begin{array}{cc}
b_{1}+\xi_{3} & \xi_{3} b_{0}-\gamma_{1} \gamma_{2} \tau_{3} \\
1 & b_{0}+\xi_{3} b_{1}
\end{array}\right] \\
& =b_{1} b_{0}+\xi_{3}^{2} b_{1}+\xi_{3} b_{1}^{2}+\gamma_{1} \gamma_{2} \tau_{3} \\
& >b_{1} b_{0}+\gamma_{1} \gamma_{2} \tau_{3} .
\end{aligned}
$$


Lembrando que $\sigma=\lambda_{1} / \xi_{1}+\left(\gamma_{1} \lambda_{2}\right) /\left(\xi_{1} \xi_{2}\right)$, temos

$$
\begin{aligned}
b_{0} & =\xi_{1} \xi_{2}-\tau_{1} \xi_{2}-\tau_{2} \gamma_{1} \\
& =\xi_{1} \xi_{2}\left[1-\tau_{1} / \xi_{1}-\left(\tau_{2} \gamma_{1}\right) /\left(\xi_{1} \xi_{2}\right)\right] \\
& =\xi_{1} \xi_{2}\left[1-\left(\tau_{1} / \xi_{1}+\left(\tau_{2} \gamma_{1}\right) /\left(\xi_{1} \xi_{2}\right)\right]\right. \\
& =\xi_{1} \xi_{2}\left[1-\left(\lambda_{1} /\left(\sigma \xi_{1}\right)+\left(\gamma_{1} \lambda_{2}\right) /\left(\xi_{1} \xi_{2} \sigma\right)\right)+g(I)\left(1 / \xi_{1}+\gamma_{1} /\left(\xi_{1} \xi_{2}\right)\right)\right] \\
& =\xi_{1} \xi_{2}\left[1-\left(\lambda_{1} / \xi_{1}+\left(\gamma_{1} \lambda_{2}\right) /\left(\xi_{1} \xi_{2}\right)\right) / \sigma+g(I)\left(1 / \xi_{1}+\gamma_{1} /\left(\xi_{1} \xi_{2}\right)\right)\right] \\
& =g(I)\left(\xi_{2}+\gamma_{1}\right) .
\end{aligned}
$$

É fácil ver que $b_{1}>\xi_{2}$ (na verdade $\left.b_{1}=\xi_{2}+q_{1}(0)>\xi_{2}+g(I)\right)$.

Portanto $b_{0} b_{1}>\gamma_{1} \xi_{2} g(I)>\gamma_{1} \gamma_{2} g(I)$.

Como $\tau_{3}=-(1-1 / \sigma) g(I)>-g(I)$, segue que

$$
b_{0} b_{1}+\gamma_{1} \gamma_{2} \tau_{3}>\left(\gamma_{1} \gamma_{2}-\gamma_{1} \gamma_{2}\right) g(I)=0
$$

Portanto segue do Teorema de Routh-Hurwitz que $q_{3}$ é um polinômio estável.

Para o caso b) usaremos o Teorema 11 do Apêndice.

Sejam $B=\left(a_{i j}\right) \in M_{(m+1 \times m+1)}$ dada por $(3.13), \bar{t}_{j}=\theta_{j}, \forall j=1, \ldots, m$, $\bar{t}_{m+1}=1 \mathrm{e}$

$$
\begin{aligned}
\sigma_{k} & =\theta_{k} /\left(\xi_{1} \theta_{1}\right) \\
& =\left(1 / \xi_{k}\right) \prod_{j=1}^{k-1} \gamma_{j} / \xi_{j}
\end{aligned}
$$

Então

$$
\begin{aligned}
\sigma & =\sum_{k=1}^{m} \lambda_{k} \sigma_{k} \\
& =\left[1 /\left(\xi_{1} \theta_{1}\right)\right] \sum_{k=1}^{m} \lambda_{k} \theta_{k}
\end{aligned}
$$

e portanto

$$
\sum_{k=1}^{m} \lambda_{k} \sigma_{k}=\xi_{1} \theta_{1} \sigma
$$

Na primeira linha temos:

$$
\sum_{j=2}^{m+1} \bar{t}_{j}\left|a_{1 j}\right|=\theta_{2} \tau_{2}+\cdots+\theta_{m} \tau_{m}+\left|\tau_{m+1}\right| .
$$


Portanto

$$
\begin{aligned}
\sum_{j=2}^{m+1} \bar{t}_{j}\left|a_{1 j}\right| & =-\theta_{1}\left(\lambda_{1} / \sigma-g(I)-\xi_{1}\right)+(1-1 / \sigma-\theta) g(I) \\
& <-\theta_{1}\left(\lambda_{1} / \sigma-g(I)-\xi_{1}\right) \\
& =-\theta_{1}\left(\tau_{1}-\xi_{1}\right) \\
& =-\bar{t}_{1} a_{11} .
\end{aligned}
$$

Na $(m+1)$-ésima linha temos:

$$
\begin{aligned}
\sum_{j=1}^{m} \bar{t}_{j}\left|a_{m+1 j}\right| & =\bar{t}_{m} \gamma_{m} \\
& =\xi_{m+1} \\
& =-\bar{t}_{m+1} a_{(m+1 \times m+1)} .
\end{aligned}
$$

Na $k$-ésima linha $(2 \leq k \leq m)$ temos:

$$
\begin{aligned}
\sum_{j \neq k}^{m+1} \bar{t}_{j}\left|a_{k j}\right| & =\bar{t}_{k-1} \gamma_{k-1} \\
& =\xi_{k} \prod_{j=k}^{m} \xi_{j+1} / \gamma_{j} \\
& =-\bar{t}_{k} a_{k k} .
\end{aligned}
$$

Consideremos as funções $\phi_{i}: \mathbb{R}^{m} \rightarrow \mathbb{R}, 2 \leq i \leq m+1$, definidas por:

$$
\phi_{i}\left(t_{1}, \ldots, t_{m}\right)=t_{i-1} \gamma_{i-1}+t_{i} a_{i i}, 2 \leq i \leq m+1 .
$$

Então

$$
\phi\left(\bar{t}_{1}, \ldots, \bar{t}_{m}\right)=0,2 \leq i \leq m+1
$$

$\mathrm{e}$

$$
\begin{aligned}
\frac{\partial\left(\phi_{2}, \ldots, \phi_{m+1}\right)}{\partial\left(t_{1}, \ldots, t_{m}\right)}\left(\bar{t}_{1}, \ldots, \bar{t}_{m}\right) & =\left[\begin{array}{ccccc}
\gamma_{1} & a_{22} & 0 & \cdots & 0 \\
0 & \gamma_{2} & a_{33} & \cdots & 0 \\
0 & 0 & \gamma_{3} & \cdots & 0 \\
\vdots & \vdots & \vdots & \ddots & \vdots \\
0 & 0 & 0 & \cdots & \gamma_{m}
\end{array}\right] \\
& \neq 0 .
\end{aligned}
$$


Logo, pelo Teorema da Funçào Inversa, existem $t_{j}>0.1 \leq j \leq m$, tais que:

$$
\phi_{i}\left(t_{1}, \ldots, t_{m}\right)<0,2 \leq i \leq m+1
$$

e que satisfazem (3.16) com $t_{i}$ no lugar de $\bar{t}_{i}$ para $1 \leq i \leq m$.

Portanto as hipóteses do Teorema 11 estão satisfeitas e a matriz $B$ é estável. 


\section{Apêndice A}

\section{Resultados Técnicos.}

Reunimos neste apêndice alguns resultados técnicos usados no texto.

\section{A.1 O Teorema de Perron-Frobenius}

Esta seção contém alguns resultados necessários para a demonstração dos Teoremas 1 e 2 do Capítulo 1.

Dada uma matriz $A_{n \times n}=\left(a_{i j}\right)$, dizemos que $A$ é irredutível se para qualquer subconjunto próprio $S \subset\{1, \ldots, n\}$ existe $i \in S$ e $j \in S^{\prime}=$ $\{1, \ldots, n\}-S$ tal que $a_{i j} \neq 0$.

Se $\left\{\lambda_{i}\right\}$ são os autovalores de uma matriz $A_{n \times n}$. então o raio espectral, $\rho(A)$, é definido por $\rho(A)=\max _{1 \leq i \leq n}\left|\lambda_{i}\right|$.

O módulo de estabilidade $s(A)$ é definido por $s(. A)=\max _{1 \leq i \leq n} \operatorname{Re} \lambda_{i}$, onde $\lambda_{i}$ são os autovalores de $A$.

A matriz $A=\left(a_{i j}\right)$ é chamada não negativa $(. t \geq 0)$ se e somente se $a_{i j} \geq 0, \quad \forall i, j$.

O seguinte resultado é devido a Perron (1907) e Frobenius (1912). (Ver [27], p. 30.)

Teorema 8 Seja $A_{n \times n}$ uma matriz não negativa e irredutível. Então

(i.) A tem um autovalor positivo igual ao seu raio espectral.

(ii.) Existe um autovetor $w>0$ associado a $\rho(A)$ (isto é. $w_{i}>0, \quad \forall i=$ $1, \ldots, n$. 
(iii.) $\rho(A)$ aumenta quando qualquer entrada de t aumenta.

(iv.) $\rho(A)$ é um autovalor simples de $A$.

Usando este resultado podemos provar o seguinte Corolário:

Corolário 3 Seja $A_{n \times n}$ uma matriz irredutivel. Suponhamos que $a_{i j} \geq 0$ sempre que $i \neq j$. Então existe um autovetor $w$ de $A$ tal que $w>0$ e o correspondente autovalor és $(A)$.

\section{Prova:}

Escolhemos $c \in \mathbb{R}^{+}$, tal que $c+a_{i i} \geq 0, \quad \forall i=1, \ldots, n$. Então $A+c I$ é uma matriz irredutível e não negativa. Assim pelo Teorema 8 . existe um autovetor positivo $w$ com autovalor igual ao raio espectral $\rho(A+c I)$.

Assim

$$
(A+c I) w=\rho(A+c I) w,
$$

desse modo

$$
A w=[\rho(A+c I)-c] w,
$$

logo $w$ é também um autovetor de $A$ e o autovalor associado a $w$ é $\rho(A+c I)-c$.

Como $\rho(A+c I)-c$ é um autovalor real, segue que $\rho(A+c I)-c \leq s(A)$.

Por outro lado se $\lambda$ é um autovalor de $A$, então $\lambda+c$ é um autovalor de $A+c I, \operatorname{logo}|\lambda+c| \leq \rho(A+c I)$, donde segue que $\operatorname{Re} \lambda \leq \rho(A+c I)-c$.

Portanto $s(A) \leq \rho(A+c I)-c$ e o Corolário está provado.

\section{A.2 Princípio da Invariância de La Salle}

Consideremos o seguinte sistema

$$
\frac{d y}{d t}=f(y)
$$

onde $f$ é de classe $\mathcal{C}^{1}$ em uma região $D$ do espaço Euclidiano $n$-dimensional ( $D$ pode ser o espaço todo) e região significa um conjunto aberto e conexo em $\mathbb{R}^{n}$. Assumiremos que $D$ contém a origem em seu interior e que a origem é uma solução de (A.1), isto é, $f(0)=0$. Escreveremos $\phi\left(t, y_{0}\right)$ para a solução de (A.1) passando por $y_{0}$ em $t=0$ e estudaremos agora o comportamento das soluçòes de (A.1), para um conjunto convexo positivamente invariante em relação a (A.1). 
Teorema 9 (Princípio da Invariância de La Salle) Seja $\Omega \subset \mathbb{R}^{n} u m$ conjunto compacto positivamente invariante em relaçio ao sistema (A.1).

Suponhamos que exista uma função $V: \Omega \rightarrow \mathbb{R}, V \in \mathcal{C}^{1}(\Omega)$ e que $V^{\prime}(y) \leq$ $0, \forall y \in \Omega$. Sejam $E=\left\{y \in \Omega: V^{\prime}(y)=0\right\} \in M$ o maior subconjunto invariante de $E$ (em relação a (A.1)). Então toda solução de (A.1) começando em $\Omega$ tende a $M$ quando $t \rightarrow \infty$.

\section{Demonstração:}

Por hipótese, $V\left(\phi\left(t, x_{0}\right)\right)$ é não crescente para $t \geq 0$ e é limitada inferiormente, $\log 0 l=\lim _{t \rightarrow+\infty} V\left(\phi\left(t, x_{0}\right)\right)$ existe.

Se $y \in w\left(x_{0}\right)$, então existe uma seqüência $\left\{t_{n}\right\}_{n \in \mathbb{N}},\left\{t_{n}\right\} \stackrel{n \rightarrow \infty}{\longrightarrow}+\infty$, tal que $\lim _{n \rightarrow \infty} \phi\left(t_{n}, x_{0}\right)=y$. Logo $V(y)=\lim _{t \rightarrow \infty} V\left(\phi\left(t_{n}, x_{0}\right)\right)=l$.

Assim $V(\phi(t, y))=\lim _{t \rightarrow \infty} V\left(\phi\left(t_{n}+t, x_{0}\right)\right)=l$ e portanto $V^{\prime}(y)=0$.

Então $w\left(x_{0}\right) \subset E$ e como $w\left(x_{0}\right)$ é invariante temos que $w\left(x_{0}\right) \subset M$.

Se $\phi\left(t, x_{0}\right) \nrightarrow M$, então existe uma seqüência $\left\{t_{n}\right\}_{n \in \mathbb{H}},\left\{t_{n}\right\} \stackrel{n \rightarrow \infty}{\longrightarrow}+\infty$, tal que $\phi\left(t_{n}, x_{0}\right) \notin V_{\varepsilon} M=\{y \in \Omega:\|x-y\|<\varepsilon$, para algum $x \in M\}$.

Mas então, existe uma subseqüência $\left\{t_{n_{k}}\right\}_{k \in \mathbb{N}},\left\{t_{n_{k}}\right\} \stackrel{k \rightarrow \infty}{\longrightarrow}+\infty$, tal que $\phi\left(t_{n_{k}}, x_{0}\right) \rightarrow \bar{x} \notin M$. Portanto $w\left(x_{0}\right) \not \subset M$. Contradição.

Obs. : Seguindo a prova do teorema, notemos que se $V$ é contínua, então o Teorema 9 é ainda verdadeiro se trocarmos $V^{\prime}$ por

$$
V^{\prime}(t)=\limsup _{h \rightarrow 0^{+}} \frac{V(y(t+h))-V(y(t))}{h} .
$$

Corolário 4 Seja $V$ uma função de classe $\mathcal{C}^{1}$ a valores reais definida em uma região $D \subset \mathbb{R}^{n}$. Suponhamos que $V(y)>0, \forall y \neq 0, V(0)=0$ e que $V^{\prime}(y)=\nabla V(y) f(y) \leq 0$ em $C$, onde $C \subset D$ é um conjunto compacto $e$ positivamente invariante em relação a (A.1) com $0 \in C$.

Suponhamos também que a origem seja o único subconjunto invariante em relação a (A.1), do conjunto $E=\left\{y \in C: V^{\prime}(y)=0\right\}$. Então a solução zero de (A.1) é globalmente assintoticamente estável em $C$.

\section{Prova:}

Como $V(y)>0, \quad \forall \quad y \neq 0, V(0)=0$ e $V^{\prime}(y) \leq 0$ em $C$, temos que a solução zero é estável em $C$ e o resultado segue do Princípio da Invariância de La Salle. 
O seguinte Lema foi usado na demonstraçào do Teorema 1.

Lema 7 Se o conjunto compacto e convexo C' é positivamente invariante em relação ao sistema (A.1), então existe ao menos uma solução constante do sistema que pertence a $C$.

Prova:

Como $f$ é contínua e tem derivadas parciais contínuas, $f$ é lipschtziana em $C$, isto é, existe $L \in \mathbb{R}$ tal que

$$
\|f(x)-f(y)\| \leq L\|x-y\|, \quad \forall x, y \in C,
$$

$L$ é chamada de constante de Lipschitz.

É então mostrado em [30] que se o sistema (A.1) tem uma solução periódica não constante de período $p$, então $p \geq \frac{2 \pi}{L}$.

Seja $U_{n}: C \rightarrow C$ uma funçào definida por $U_{n}(c)=\phi\left(\frac{1}{n}, c\right)$, onde $\phi$ é a solução de (A.1). Pelo Teorema do Ponto Fixo de Brower existe $c_{n} \in C$ tal que $U_{n}\left(c_{n}\right)=\phi\left(\frac{1}{n}, c_{n}\right)=c_{n}$, para cada $n$.

Então $\phi\left(t, c_{n}\right)$ é uma solução periódica de período pelo menos $\frac{1}{n}$.

Agora escolha $M$ grande suficiente para que $\frac{1}{M}<\frac{2 \pi}{L}$.

Assim $\phi\left(t, c_{M}\right)$ é periódica de período menor do que $\frac{2 \pi}{L}$ e portanto $\phi\left(t, c_{M}\right)$ deve ser uma solução constante.

\section{A.3 Estabilidade de Pontos Críticos.}

O Teorema 10 pode ser visto em [23] e o Teorema 11 em ([18], p. 159).

Teorema 10 (Teorema de Routh-Hurwitz) Seja

$$
a_{0} p^{n}+a_{1} p^{n-1}+\cdots+a_{n}, a_{0}>0,
$$

um polinômio arbitrário de grau $n$ a coeficientes reais e tomemos a matriz 
$Q$ de ordem $n$ como segue abaixo:

$$
Q=\left(\begin{array}{ccccc}
a_{1} & a_{3} & a_{5} & \ldots & 0 \\
a_{0} & a_{2} & a_{4} & \ldots & 0 \\
0 & a_{1} & a_{3} & \ldots & 0 \\
\vdots & \vdots & & & \vdots \\
0 & 0 & \ldots & a_{n-2} & a_{n}
\end{array}\right)
$$

então o polinômio (A.2) é estável se e somente se todos os menores principais da matriz $Q$ são positivos.

Teorema 11 Se $B=\left(a_{i j}\right) \in M_{(m+1 \times m+1)}(\mathbb{C})$ e existem números positivos $t_{1}, \ldots, t_{m+1}$ tais que:

$$
\sum_{j \neq i}^{m+1} t_{j}\left|a_{i j}\right|<-t_{i} \operatorname{Re}\left(a_{i i}\right), \quad i=1, \ldots, m+1,
$$

então $B$ é estável (todo autovalor tem parte real negativa).

\section{A.4 O Teorema de Bifurcação de Hopf.}

Nesta seção enunciaremos uma forma simplificada do Teorema de Bifurcação de Hopf suficiente para os nossos propósitos (para um enunciado mais completo ver ([11], p. 270) e ([16], pp. 201-203)).

Teorema 12 Suponhamos que temos um campo bidimensional a um parâmetro $k$

$$
\left(\begin{array}{c}
i \\
r
\end{array}\right)^{\prime}=\left(\begin{array}{c}
F(i, r, k) \\
G(i, r, k)
\end{array}\right),
$$

onde $F$ e $G$ são de classe $\mathcal{C}^{3}$. Assumimos que o sistema tem um único ponto de equilíbrio $(i(k), r(k))$ para $k \approx k_{0}$ e a matriz Jacobiana

$$
J(k)=\left.\left(\begin{array}{cc}
F_{i} & F_{r} \\
G_{i} & G_{r}
\end{array}\right)\right|_{(i=i(k), r=r(k))}
$$

tem um par de autovalores complexos conjugados $\lambda(k), \bar{\lambda}(k)$ satisfazendo

$$
\frac{d}{d k} \operatorname{Re} \lambda\left(k_{0}\right) \neq 0, \omega_{0}=\operatorname{Im} \lambda\left(k_{0}\right)>0 \text { e Re } \lambda\left(k_{0}\right)=0 .
$$


Então existem $\mu_{0}>0$, funçòes escalares $k^{*}(\mu) . \omega^{*}(\mu)$, funçós periódicas $i^{*}(\mu)$ e $r^{*}(\mu)$ de período $\omega^{*}(\mu)$, todas de classe $\mathcal{C}^{1}$ para $|\mu|<\mu_{0}$ tais que $\left(i^{*}(\mu), r^{*}(\mu)\right)$ é solução de $(A .3), k^{*}(0)=k_{0} e \omega^{*}(0)=\frac{2 \pi}{\omega_{0}}$.

Além disso, se $A>0$ onde

$$
\begin{aligned}
A= & \left(\omega^{2} C\right)^{-1}\left[\left(B\left(F_{i i i}+G_{i i r}\right)+2 D\left(F_{i i r}+G_{i r r}\right)+C\left(F_{i r r}+G_{r r r}\right)\right) \omega^{2}\right. \\
& +\left(D F_{i i}+C F_{i r}\right)\left(B F_{i i}+2 D F_{i r}+C F_{r r}\right) \\
& -\left(D G_{r r}+B G_{i r}\right)\left(B G_{i i}+2 D G_{i r}+C G_{r r}\right) \\
& -B^{2} F_{i i} G_{i i}-D B\left(F_{i r} G_{i i}+F_{i i} G_{i r}\right) \\
& \left.+C^{2} F_{r r} G_{r r}+D C\left(F_{i r} G_{r r}+F_{r r} G_{i r}\right)\right]
\end{aligned}
$$

sendo que

$$
D=F_{i}=-G_{r}, B=-F_{r}, C=G_{i}, \omega^{2}=B C-D^{2}
$$

e todas as derivadas são calculadas em $\left(i^{*}\left(k_{0}\right), r^{*}\left(k_{0}\right), k_{0}\right)$, então a bifurcação é subcrítica, isto é, as soluções periódicas são instáveis. Se $A<0$ a bifurcação é supercrítica, isto é, as soluções periódicas são estáveis. 


\section{Referências Bibliográficas}

[1] Anderson, R. M.; May, R. M., Infectious Diseases of Humans. Dynamics and Control. Oxford University Press, Inc. New York (1993).

[2] Aronsson, Gunnar; Mellander Ingvar, A Deterministic Model in Biomathematics. Asymptotic Behavior and Threshold Conditions. Math. Biosc. 49 (1980), 207-222.

[3] Bailey, N. T. J., The Mathematical Theory of Infectious Diseases and its Aplications. 2 nd edition, C. Griffin and Co. Ltd. London (1975).

[4] Bartle, Robert G., The Elements of Real Analysis. 2 nd edition. John Wiley \& Sons, Inc. New York (1976).

[5] Busenberg, S.; Driessche, P. van den, Analysis of a Disease Transmission Model in a Population with Varying Size. J. Math. Biol. 28 (1990), 257270.

[6] Cooke, K. L.; Yorke, J. A., Some Equations Modelling Growth Processes and Gonorrhea Epidemics. Math Biosc. 16 (1973), 75-101.

[7] Derrick, W. R.; Driessche, P. van den. A Disease Transmission Model in a Nonconstant Population. J. Math. Biol. 34 (1993), 495-512.

[8] Gantmacher, F. R., The Theory of Matrices. Vol. 2, Chelsea Publishing Company, New York (1964).

[9] Guckenheimer, P. H., Nonlinear Oscillations. Dynamical Systems and Bifurcations of Vector Fields. Applied Mathematical Sciences Vol. 42. Springer, New York (1990).

[10] Hahn, W., Stability of Motion.. Springer, Berlin Heidelberg New York (1967). 
[11] Hale, J.. Ordinary Differential Equations. Robert E. Krieger Publishing Company, Inc. Malabar, Florida (1980).

[12] Hethcote, H. W.; Ark, J. W. van, Modeling HI' Transmission and AIDS in the United States. Lecture Notes in Biomathematics. Vol. 95. Springer, Germany (1992).

[13] Hethcote, H. W.; Yorke, J. A., Gonorrhea Transmission Dynamics and Control. Lecture Notes in Biomathematics. Vol. 56. Springer, Berlin (1984).

[14] Honig, C. S., Aplicações da Topologia à Analise. Projeto Euclides, CNPq (1976).

[15] Lajmanovich, Ana; Yorke, J. A., A Deterministic Model for Gonorrhea in a Nonhomogeneous Population. Math. Biosc. 28 (1976), 221-236.

[16] Liu, W.-M.; Levin, S. A.; Iwasa, Y., Influence of Nonlinear Incidence Rates Upon the Behavior of SIRS Epidemiological Models. J. Math. Biol. 23 (1986), 187-204.

[17] Kermack, W. O.; MacKendric, A. G., A Contribution to the Mathematical Theory of Epidemics. Proc. R. Soc. A115 (1927), 700-721.

[18] Marcus, M.; Minc, H., A Survey Matrix Theory and Matrix Inequalities. Allyn and Bacon, Inc. Boston (1964).

[19] Marsden, J. E.; McCracken, M., The Hopf Bifurcations and its Aplications.. Applied Mathematical Sciences. Vol. 19. Springer, New York (1976).

[20] Massad, E., Mathematical and Computer Models in Epidemiology. (1995). Notas não publicadas.

[21] Massad, E., Modelos Matemáticos. In Forattini, O. P., editor, Ecologia, Epidemia e Sociedade. Editora Artes Médicas (1992).

[22] Neto, R. B. et al., A AIDS Não Morreu. Folha de São Paulo, domingo, 20/04/97, 5 o caderno.

[23] Pontriaguine, L., Équations Différentielles Ordinaires. Éditions Mir, Moscou (1969). 
[24] Raimundo, S. M., Uma Abordagem Determinística da Interação de Doenças. Aids e Tb num Presídio. Tese de Doutorado. IMECC - UNICAMP (1996).

[25] Sotomayor, J., Lições de Equações Diferenciais Ordinárias. Projeto Euclides, CNPq (1979).

[26] Struchiner, C. J.; Massad, E.; Neto, R. A. N., Introdução à Dinâmica Populacional das Doenças Transmissíveis. (1994). Notas nào publicadas.

[27] Varga, R., Matrix Iterative Analysis. Prentice-Hall, Englewood Cliffs, N. J. (1965).

[28] Waltman, P.. Deterministic Threshold Models in Theory of Epidemics. Lecture Notes in Biomathematics. Vol. 1. Springer, New York (1974).

[29] Yorke, J. A., Invariance for Ordinary Differential Equations. Math. Syst. Theory 1 (1967), 353-372.

[30] Yorke, J. A., Periods of Periodic Solutions and the Lipschitz Constant. Proc. Am. Math. Soc. 22 (1969), 509-512. 